\title{
Identification of survival-associated key genes and long non-coding RNAs in glioblastoma multiforme by weighted gene co-expression network analysis
}

\author{
$\mathrm{XIN} \mathrm{CHEN}^{1}, \mathrm{CHANGCUN} \mathrm{PAN}^{1}, \mathrm{CHENG} \mathrm{XU}^{1}$, YU SUN ${ }^{1}, \mathrm{YIBO} \mathrm{GENG}^{1}, \mathrm{LU} \mathrm{KONG}^{1}, \mathrm{XIONG} \mathrm{XIAO}^{1}$, \\ ZITONG ZHAO $^{2}$, WEI ZHOU ${ }^{2}$, LIJIE HUANG ${ }^{2}$, YONGMEI SONG ${ }^{2}$ and LIWEI ZHANG ${ }^{1}$ \\ ${ }^{1}$ Department of Neurosurgery, Beijing Tiantan Hospital, Capital Medical University, Beijing 100050; \\ ${ }^{2}$ State Key Laboratory of Molecular Oncology, National Cancer Center, Cancer Hospital, \\ Chinese Academy of Medical Sciences and Peking Union Medical College, Beijing 100021, P.R. China
}

Received September 28, 2018; Accepted February 14, 2019

DOI: $10.3892 / \mathrm{ijmm} .2019 .4101$

\begin{abstract}
Glioblastoma multiforme (GBM) is the most common and aggressive primary malignant brain tumour. However, the causes of GBM are not clear, and the prognosis remains poor. The aim of the present study was to elucidate the key coding genes and long non-coding RNAs (lncRNAs) associated with the survival time of GBM patients by obtaining the RNA expression profiles from the Chinese Glioma Genome Atlas database and conducting weighted gene co-expression network analysis. Modules associated with overall survival (OS) were identified, and Gene Ontology and pathway enrichment analyses were performed. The hub genes of these modules were validated via survival analysis, while the biological functions of crucial lncRNAs were also analysed in the publicly available data. The results identified a survival-associated
\end{abstract}

Correspondence to: Dr Liwei Zhang, Department of Neurosurgery, Beijing Tiantan Hospital, Capital Medical University, 6 Tiantanxili, Dongcheng, Beijing 100050, P.R. China

E-mail: 112016000201@ccmu.edu.cn

Dr Yongmei Song, State Key Laboratory of Molecular Oncology, National Cancer Center, Cancer Hospital, Chinese Academy of Medical Sciences and Peking Union Medical College, 17 Panjiayuannanli, Chaoyang, Beijing 100021, P.R. China

E-mail: symlh2006@163.com

Abbreviations: WGCNA, weighted gene co-expression network analysis; GBM, glioblastoma multiforme; lncRNA, long non-coding RNA; GO, Gene Ontology; CNS, central nervous system; CGGA, Chinese Glioma Genome Atlas; PPI, protein-protein interaction; OS, overall survival; TCGA, The Cancer Genome Atlas; TOM, topological overlap matrix; KEGG, Kyoto Encyclopaedia of Genes and Genomes; BP, biological processes; CC, cell composition; MF, molecular function; ECM, extracellular matrix; OXPHOS, oxidative phosphorylation

Key words: bioinformatics analysis, glioblastoma multiforme, long non-coding RNA, prognosis, weighted gene co-expression network analysis module with 195 key genes. Among them, 33 key genes were demonstrated to be associated with OS, and the majority of these were involved in extracellular matrix-associated and tyrosine kinase receptor signalling pathways. Furthermore, LOC541471 was identified as an OS-associated lncRNA, and was reported to be involved in the oxidative phosphorylation of GBM with pleckstrin-2. These findings may significantly enhance our understanding on the aetiology and underlying molecular events of GBM, while the identified candidate genes may serve as novel prognostic markers and potential therapeutic targets for GBM.

\section{Introduction}

Glioblastoma multiforme (GBM) is an aggressive carcinoma that was first described in 1800 (1). According to the World Health Organisation classification of tumours of the central nervous system (CNS), GBM is classified as a grade IV malignant glial neoplasm with astrocytic differentiation (2). As one of the most commonly diagnosed malignant CNS tumours, it accounts for $45.6 \%$ of primary malignant brain tumours, with an annual incidence of 3.1 cases per 100,000 individuals in the United States (3). GBM is considered to be one of the most malignant primary intracranial tumours and has a dismal prognosis, $<5 \%$ of patients surviving 5 years after diagnosis (3). Even after microsurgery and adjuvant temozolomide-based radio-chemotherapy or radiotherapy alone, the prognosis of patients remains poor, with a median survival of 14 months (4). In recent years, clinical trials of angiogenesis inhibitor therapies have been performed on patients with recurrent GBM; however, no survival benefit was achieved (5). Furthermore, a randomised phase III clinical trial of epidermal growth factor receptor (EGFR) variant III-targeted drugs failed to confirm any survival benefit compared with the control group (6). Therefore, searching for novel candidate genes and studying the underlying mechanisms driving tumourigenesis are important to generate new therapeutic targets.

The development of microarray and high-throughput sequencing technology has provided new methods for investigating the molecular mechanisms underlying tumour 
behaviour and for screening drug targets. In 2012, the Chinese Glioma Genome Atlas (CGGA) was built, which provides genomic and clinical data for hundreds of samples that have been examined by whole-genome sequencing, whole-exome sequencing, DNA methylation microarray detection, as well as microRNA (miRNA), circular RNA, long non-coding RNA (lncRNA) and mRNA sequencing (7). This database represents a landmark achievement in glioma research in China.

Weighted gene co-expression network analysis (WGCNA) is a powerful method for describing the correlations among genes using microarray or RNA sequencing data. WGCNA can be applied to search for candidate biomarkers or therapeutic targets, as well as phenotype-associated modules or gene clusters based on co-expression networks (8). Compared with other analytical methods, WGCNA has the advantage of summarising and standardising the methods and functions in the R software package. Currently, this systematic method is widely used to study a number of complex diseases, particularly cancer. For instance, Lv et al (9) observed that LINC01314 functions as a tumour suppressor in hepatoblastoma. Furthermore, Clarke et al (10) indicated that KCNK5 was associated with poor outcomes of the basal-like molecular subtype in breast cancer. Using this analysis, the pathways involved in the co-expression network of cancer models and target genes can be identified. However, relevant research is currently lacking in GBM.

The present study aimed to explore the underlying molecular mechanisms, and identify novel prognostic biomarkers and treatment targets of GBM. The expression profiles of lncRNAs and mRNAs in GBM compared with those of normal controls were investigated, and differentially expressed RNAs were identified from the CGGA database. Next, the enriched pathways participating in the tumourigenesis of GBM were determined, and protein-protein interaction (PPI) networks were constructed. Finally, using public databases, potential prognostic biomarkers were confirmed, and the clinical significance and biological functions of survival-associated lncRNAs were identified.

\section{Materials and methods}

Data collection. RNA sequencing and clinical data of GBM patients were obtained from the CGGA database (http://www. cgga.org.cn). The gene expression levels were measured in terms of fragments per kilobase of transcript per million mapped reads. Various clinical data were also downloaded from the database, which included the patient gender, age, The Cancer Genome Atlas (TCGA) subtype, overall survival (OS), radiotherapy and chemotherapy details, and the mutation status of the genes isocitrate dehydrogenase (IDH), tumour protein p53 (TP53), EGFR, ATRX and enhancer of zeste homolog 2 (EZH2) $(11,12)$. All cases with pathological diagnosis of GBM were included in the analysis. The exclusion criteria applied in the present study were as follows: i) Histologic confirmation of the diagnosis of any brain tumour type other than primary GBM; ii) history of radiotherapy or chemotherapy prior to histologic diagnosis; iii) patients with missing follow-up records; and iv) missing mutation information for the five aforementioned genes. According to these criteria, a total of 88 GBM samples were selected for inclusion in the current study (Table I). Furthermore, another gene expression and
Table I. Summary of patient characteristics.

\begin{tabular}{|c|c|}
\hline Characteristic & Value \\
\hline No. of patients & 88 \\
\hline \multicolumn{2}{|l|}{ Age } \\
\hline$\geq 40$ years & 73 \\
\hline$<40$ years & 15 \\
\hline \multicolumn{2}{|l|}{ Sex } \\
\hline Male & 55 \\
\hline Female & 33 \\
\hline \multicolumn{2}{|l|}{ TCGA subtype } \\
\hline Classical & 32 \\
\hline Mesenchymal & 36 \\
\hline Neural & 7 \\
\hline Proneural & 13 \\
\hline \multicolumn{2}{|l|}{ OS } \\
\hline$\geq 12$ months & 43 \\
\hline$<12$ months & 45 \\
\hline History of radiotherapy & 59 \\
\hline History of chemotherapy & 52 \\
\hline \multicolumn{2}{|l|}{ Gene mutation } \\
\hline IDH & 12 \\
\hline TP53 & 44 \\
\hline EGFR & 23 \\
\hline ATRX & 9 \\
\hline $\mathrm{EZH} 2$ & 13 \\
\hline
\end{tabular}

TCGA, The Cancer Genome Atlas; OS, overall survival; IDH, isocitrate dehydrogenase; TP53, tumour protein p53; EGFR, epidermal growth factor receptor; EZH2, enhancer of zeste homolog 2.

clinical dataset of GBM patients was downloaded from the TCGA database (https://cancergenome.nih.gov/), from which 162 GBM cases were selected. The dataset obtained from TCGA was analysed, and served as the validation dataset.

Construction of the gene co-expression network and identification of preserved modules. First, the expression data profiles from the CGGA were tested to confirm that they were suitable for the analysis. The standard deviation value for all samples of each gene was calculated, and the top 5,000 genes with the lowest standard deviation values were selected for subsequent analysis. Next, the co-expression network of genes was constructed using the WGCNA package in $\mathrm{R}(8)$. To calculate the scale-free topology fitting index $\mathrm{r}^{2}$ that corresponded to different soft-thresholding parameter $\beta$ values, functional pickSoftThreshold was used, and the $\beta$ value was selected if $\mathrm{r}^{2}$ reached 0.9 . The soft-thresholding power $\beta$ value was then set to 6 , and the minModuleSize was set to 30 . Subsequently, the gene expression profile was transformed into an adjacency matrix and a topological overlap matrix (TOM), which was defined as the sum of adjacency between the gene and all other genes for network generation. Next, the corresponding dissimilarity of TOM (dissTOM) was calculated, and dissTOM-based hierarchical clustering was used to produce 
A
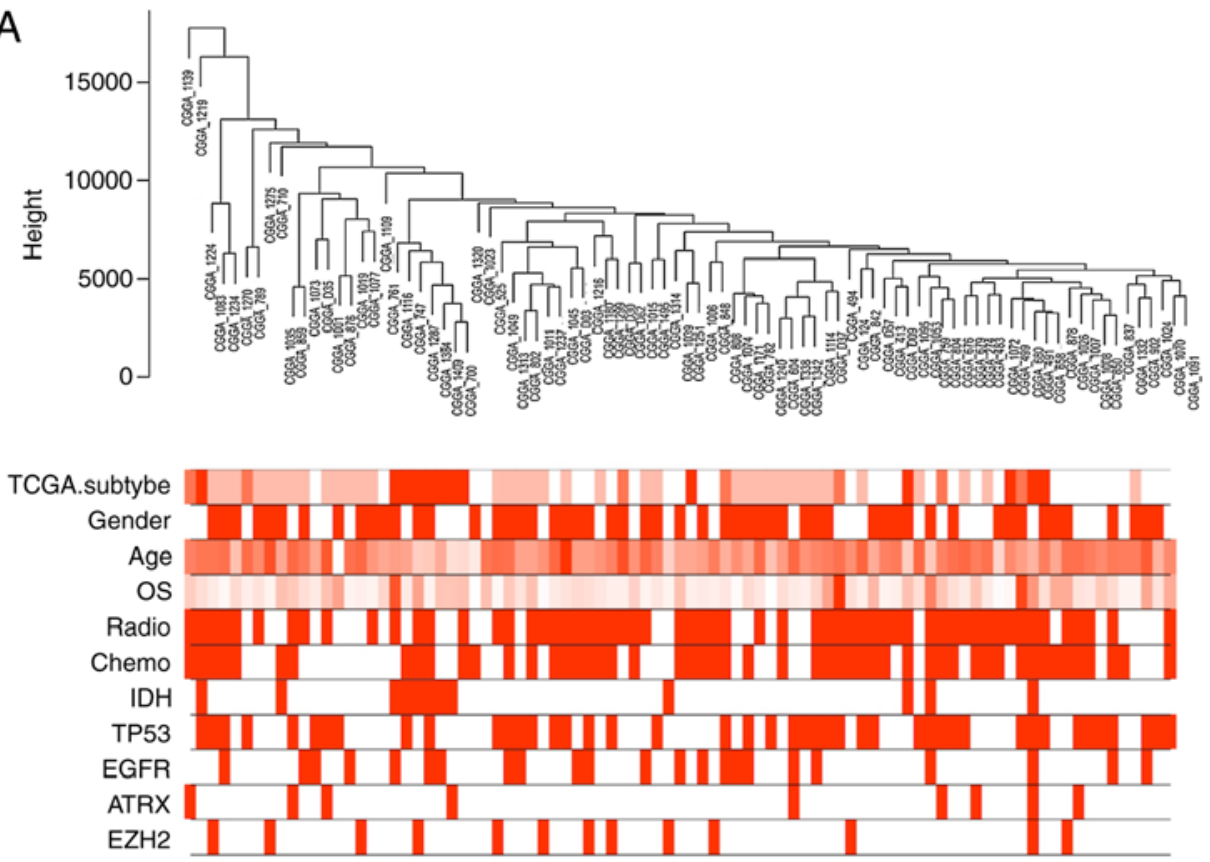

B
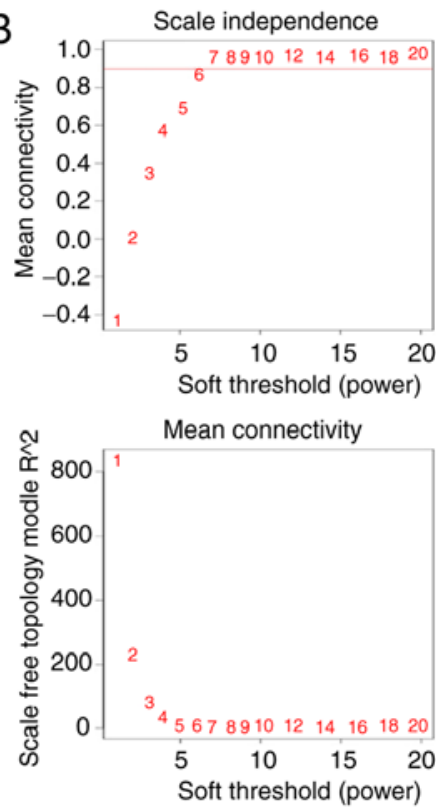
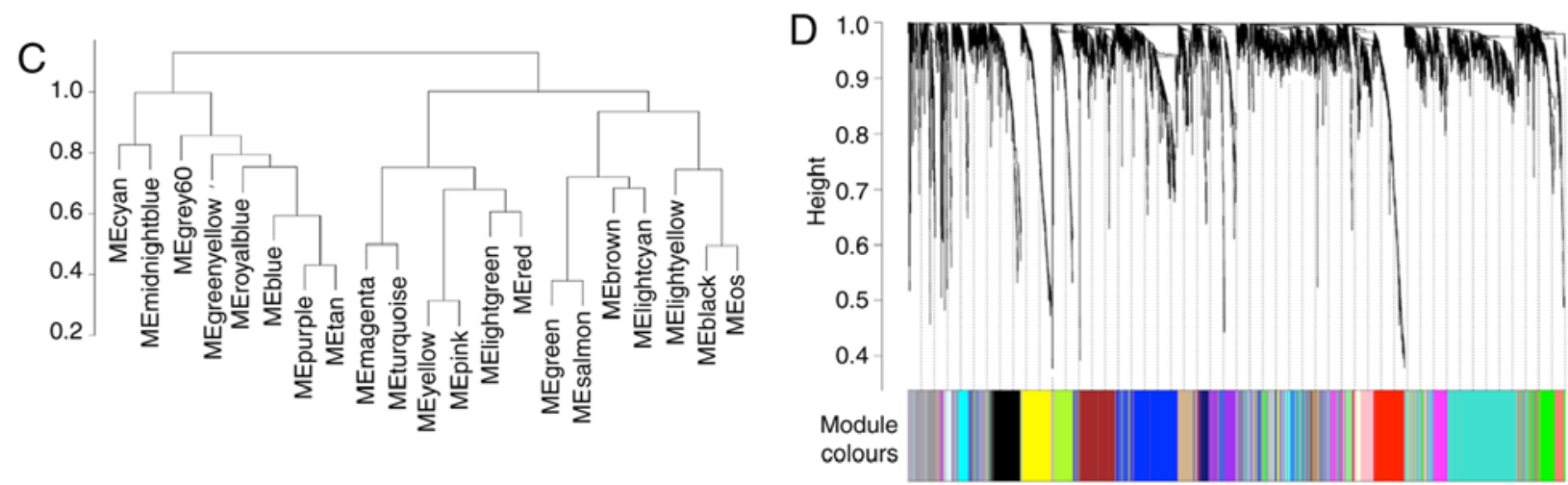

Figure 1. Network visualization plots of weighted gene co-expression network analysis. (A) Dendrogram of samples and heatmap of clinical and molecular traits. (B) Analysis of network topology for different soft-thresholding powers. The higher panel displays the influence of soft-thresholding power (x-axis) on the scale-free fit index (y-axis). The lower panel shows the influence of soft-thresholding power (x-axis) on the mean connectivity (degree; $y$-axis). (C) Clustering of MEs. Hierarchical clustering of module eigengenes that summarise the modules yielded in the clustering analysis. Joint branches of the dendrogram represent genes that are positively correlated. (D) Dendrogram of selected genes, indicating clusters with dissimilarity based on topological overlap, along with the assigned module colours. ME, module eigengene; CGGA, Chinese Glioma Genome Atlas; TCGA, The Cancer Genome Atlas; OS, overall survival; IDH, isocitrate dehydrogenase; TP53, tumour protein p53; EGFR, epidermal growth factor receptor; EZH2, enhancer of zeste homolog 2.

a hierarchical clustering dendrogram of genes. Modules of clustered genes were then generated using the Dynamic Tree Cut algorithm. The module eigengene was calculated using the function moduleEigengenes, and a number of modules were merged according to a cut-off line for the module dendrogram. The interactions (correlations) of each module were analysed and visualised by heatmaps. To identify modules associated with patient characteristics, the Pearson's correlation test was used to evaluate the correlation of module eigengenes with the clinical traits, OS and mutation status, and correlations with $\mathrm{P}$-values of $<0.05$ were considered to be statistically significant.

Gene ontology $(G O)$ and pathway enrichment analysis. The functional enrichment of the genes of the identified module was assessed based on GO terms (13) and Kyoto Encyclopaedia of Genes and Genomes (KEGG) pathway (14) annotations. GO term analyses were performed using the DAVID database (https://david.ncifcrf.gov/) and Panther database (http://www. pantherdb.org) (15), which are essential tools for the success of high-throughput gene function analysis. Pathway analysis was also conducted using multiple online databases, including the DAVID database, KEGG pathway database (http://www.genome.jp/kegg) and STRING online database (http://string-db.org) (16). P-values of $<0.05$ were considered to denote statistically significant differences in GO term enrichment and KEGG pathway analyses, and the false discovery rate was utilised to correct the $\mathrm{P}$-values.

PPI network construction and analysis. To identify the gene-encoded proteins and construct the PPI network of the identified module, the genes were mapped to the STRING database. The results obtained from this database were then imported into Cytoscape software (version 3.6.0; https://cytoscape.org/) to analyse the interactional associations among the gene-encoding proteins and their degrees in GBM (17). In addition, significant genes from the PPI network complex were 


\begin{tabular}{|c|c|c|c|c|c|c|c|c|c|c|c|c|}
\hline & & & & & Modul & -trait corr & lation & & & & & \\
\hline MEmagenta & $\begin{array}{l}0.19 \\
(0.07)\end{array}$ & $\begin{array}{l}-0.22 \\
(0.04)\end{array}$ & $\begin{array}{l}-0.14 \\
(0.2)\end{array}$ & $\begin{array}{l}-0.12 \\
(0.3)\end{array}$ & $\begin{array}{l}-0.053 \\
(0.6)\end{array}$ & $\begin{array}{l}0.018 \\
(0.9)\end{array}$ & $\begin{array}{l}0.31 \\
(0.003)\end{array}$ & $\begin{array}{l}-0.17 \\
(0.1)\end{array}$ & $\begin{array}{l}.02 \\
(0.06)\end{array}$ & $\begin{array}{l}-0.0031 \\
(1)\end{array}$ & $\begin{array}{l}0.16 \\
(0.1)\end{array}$ & \\
\hline MEturquoise & $\begin{array}{l}-0.18 \\
(0.09)\end{array}$ & $\begin{array}{l}.0 .14 \\
(0.2)\end{array}$ & $\begin{array}{l}0.13 \\
(0.2)\end{array}$ & $\begin{array}{l}-0.24 \\
(0.23)\end{array}$ & $\begin{array}{l}.0 .11 \\
(0.3)\end{array}$ & $\begin{array}{l}-0.034 \\
(0.8)\end{array}$ & $\begin{array}{l}-0.044 \\
(0.7)\end{array}$ & $\begin{array}{l}-0.16 \\
(0.1)\end{array}$ & $\begin{array}{l}.02 \\
(0.07)\end{array}$ & $\begin{array}{l}0.026 \\
(0.8)\end{array}$ & $\begin{array}{l}0.24 \\
(0.03)\end{array}$ & $\Gamma 1$ \\
\hline MElightyellow & $\begin{array}{l}-0.14 \\
(0.2)\end{array}$ & $\begin{array}{l}.0 .14 \\
(0.2)\end{array}$ & $\begin{array}{l}0.05 \\
(0.6)\end{array}$ & $\begin{array}{l}0.068 \\
(0.5)\end{array}$ & $\begin{array}{l}-0.13 \\
(0.2)\end{array}$ & $\begin{array}{l}-0.094 \\
(0.4)\end{array}$ & $\begin{array}{l}-0.015 \\
(0.9)\end{array}$ & $\begin{array}{l}-0.18 \\
(0.1)\end{array}$ & $\begin{array}{l}-0.1 \\
(0.3)\end{array}$ & $\begin{array}{l}0.025 \\
(0.8)\end{array}$ & $\begin{array}{l}0.015 \\
0.99\end{array}$ & \\
\hline MEpink & $\begin{array}{l}-0.063 \\
(0.6)\end{array}$ & $\begin{array}{l}-0.044 \\
(0.7)\end{array}$ & $\begin{array}{l}-0.12 \\
(0.3)\end{array}$ & $\begin{array}{l}-0.021 \\
(0.8)\end{array}$ & $\begin{array}{l}-0.19 \\
(0.08)\end{array}$ & $\begin{array}{l}-0.011 \\
(0.9)\end{array}$ & $\begin{array}{l}0.21 \\
(0.06)\end{array}$ & $\begin{array}{l}-0.26 \\
(0.01)\end{array}$ & $\begin{array}{l}-0.15 \\
(0.2)\end{array}$ & $\begin{array}{l}.0 .057 \\
(0.6)\end{array}$ & $\begin{array}{l}0.23 \\
(0.03)\end{array}$ & \\
\hline MElightgreen & $\begin{array}{l}0.12 \\
(0.3)\end{array}$ & $\begin{array}{l}.02 \\
(0.06)\end{array}$ & $\begin{array}{l}.0 .062 \\
(0.6)\end{array}$ & $\begin{array}{l}0.028 \\
(0.8)\end{array}$ & $\begin{array}{l}0.028 \\
(0.8)\end{array}$ & $\begin{array}{l}0.14 \\
(0.2)\end{array}$ & $\begin{array}{l}0.097 \\
(0.4)\end{array}$ & $\begin{array}{l}-0.16 \\
(0.1)\end{array}$ & $\begin{array}{l}.0 .11 \\
(0.3)\end{array}$ & $\begin{array}{l}0.28 \\
(0.009)\end{array}$ & $\begin{array}{l}0.024 \\
(0.8)\end{array}$ & \\
\hline MEred & $\begin{array}{l}-0.11 \\
(0.3)\end{array}$ & $\begin{array}{l}0.046 \\
(0.7)\end{array}$ & $\begin{array}{l}.0 .22 \\
(0.04)\end{array}$ & $\begin{array}{l}-0.15 \\
(0.2)\end{array}$ & $\begin{array}{l}-0.18 \\
(0.09)\end{array}$ & $\begin{array}{l}0.087 \\
(0.4)\end{array}$ & $\begin{array}{l}-0.031 \\
(0.8)\end{array}$ & $\begin{array}{l}-0.17 \\
(0.1)\end{array}$ & $\begin{array}{l}.0 .12 \\
(0.3)\end{array}$ & $\begin{array}{l}0.022 \\
(0.8)\end{array}$ & $\begin{array}{l}-0.0097 \\
(0.9)\end{array}$ & \\
\hline MEblack & $\begin{array}{l}0.3 \\
(0.005)\end{array}$ & $\begin{array}{l}-0.17 \\
(0.1)\end{array}$ & $\begin{array}{l}-0.079 \\
(0.5)\end{array}$ & $\begin{array}{l}0.51 \\
(66-07)\end{array}$ & $\begin{array}{l}.0 .011 \\
(0.9)\end{array}$ & $\begin{array}{l}-0.039 \\
(0.7)\end{array}$ & $\begin{array}{l}0.16 \\
(0.1)\end{array}$ & $\begin{array}{l}-0.027 \\
(0.8)\end{array}$ & $\begin{array}{l}.0 .13 \\
(0.2)\end{array}$ & $\begin{array}{l}0.096 \\
(0.4)\end{array}$ & $\begin{array}{l}-0.1 \\
(0.4)\end{array}$ & \\
\hline MEyellow & $\begin{array}{l}0.37 \\
(40.04)\end{array}$ & $\begin{array}{l}-0.11 \\
(0.3)\end{array}$ & $\begin{array}{l}-0.11 \\
(0.3)\end{array}$ & $\begin{array}{l}0.17 \\
(0.1)\end{array}$ & $\begin{array}{l}0.033 \\
(0.8)\end{array}$ & $\begin{array}{l}0.11 \\
(0.3)\end{array}$ & $\begin{array}{l}0.12 \\
(0.3)\end{array}$ & $\begin{array}{l}0.12 \\
(0.3)\end{array}$ & $\begin{array}{l}-0.024 \\
(0.8)\end{array}$ & $\begin{array}{l}0.17 \\
(0.1)\end{array}$ & $\begin{array}{l}-0.14 \\
(0.2)\end{array}$ & \\
\hline MEgreen & $\begin{array}{l}-0.15 \\
(0.2)\end{array}$ & $\begin{array}{l}-0.062 \\
(0.6)\end{array}$ & $\begin{array}{l}-0.067 \\
(0.5)\end{array}$ & $\begin{array}{l}-0.14 \\
(0.2)\end{array}$ & $\begin{array}{l}.0 .068 \\
(0.5)\end{array}$ & $\begin{array}{l}0.066 \\
(0.5)\end{array}$ & $\begin{array}{l}0.099 \\
(0.4)\end{array}$ & $\begin{array}{l}-0.23 \\
(0.03)\end{array}$ & $\begin{array}{l}-0.14 \\
(0.2)\end{array}$ & $\begin{array}{l}-0.076 \\
(0.5)\end{array}$ & $\begin{array}{l}0.055 \\
(0.6)\end{array}$ & \\
\hline MEsalmon & $\begin{array}{l}0.1 \\
(0.3)\end{array}$ & $\begin{array}{l}0.0 .44 \\
(0.7)\end{array}$ & $\begin{array}{l}.0 .042 \\
(0.7)\end{array}$ & $\begin{array}{l}-0.02 \\
(0.9)\end{array}$ & $\begin{array}{l}.0 .11 \\
(0.3)\end{array}$ & $\begin{array}{l}-0.06 \\
(0.6)\end{array}$ & $\begin{array}{l}0.044 \\
(0.7)\end{array}$ & $\begin{array}{l}-0.12 \\
(0.3)\end{array}$ & $\begin{array}{l}-0.088 \\
(0.4)\end{array}$ & ${ }^{-0.0073}$ & $\begin{array}{l}-0.11 \\
(0.3)\end{array}$ & \\
\hline MEbrown & $\begin{array}{l}0.54 \\
(60-08)\end{array}$ & $\begin{array}{l}.0 .19 \\
(0.08)\end{array}$ & $\frac{-0.45}{(10.05)}$ & $\begin{array}{r}0.28 \\
(0.009)\end{array}$ & $\begin{array}{l}0.0025 \\
\text { (1) }\end{array}$ & $\begin{array}{l}0.16 \\
(0.1)\end{array}$ & $\begin{array}{l}0.65 \\
(10-11)\end{array}$ & $\begin{array}{l}-0.14 \\
(0.2)\end{array}$ & $\begin{array}{l}-0.057 \\
(0.6)\end{array}$ & $\begin{array}{l}0.04 \\
(0.7)\end{array}$ & $\begin{array}{l}0.034 \\
(0.8)\end{array}$ & -0 \\
\hline MElightcyan & $\begin{array}{l}0.21 \\
(0.05)\end{array}$ & $\begin{array}{l}0.026 \\
(0.8)\end{array}$ & $\begin{array}{l}-0.12 \\
(0.3)\end{array}$ & $\begin{array}{l}0.23 \\
(0.03)\end{array}$ & $\begin{array}{l}0.077 \\
(0.5)\end{array}$ & $\begin{array}{l}0.15 \\
(0.2)\end{array}$ & $\begin{array}{l}0.058 \\
(0.6)\end{array}$ & $\begin{array}{l}0.096 \\
(0.4)\end{array}$ & $\begin{array}{l}-0.068 \\
0.5)\end{array}$ & $\begin{array}{l}0.0074 \\
(0.9)\end{array}$ & $\begin{array}{l}.0 .13 \\
(0.2)\end{array}$ & \\
\hline MEcyan & $\begin{array}{l}-0.22 \\
(0.04)\end{array}$ & $\begin{array}{l}0.06 \\
(0.6)\end{array}$ & $\begin{array}{l}-0.06 \\
(0.6)\end{array}$ & $\begin{array}{l}0.022 \\
(0.8)\end{array}$ & $\begin{array}{l}.0 .094 \\
(0.4)\end{array}$ & $\begin{array}{l}0.011 \\
(0.9)\end{array}$ & $\begin{array}{l}-0.11 \\
(0.3)\end{array}$ & $\begin{array}{l}.0 .046 \\
0.77)\end{array}$ & $\begin{array}{l}-0.051 \\
(0.6)\end{array}$ & $\begin{array}{l}0.01 \\
(0.9)\end{array}$ & $\begin{array}{l}-0.11 \\
(0.3)\end{array}$ & \\
\hline MEmidnightblue & $\begin{array}{l}-.0 .38 \\
(30.04)\end{array}$ & $\begin{array}{l}0.023 \\
(0.8)\end{array}$ & $\begin{array}{l}0.23 \\
(0.03)\end{array}$ & $\begin{array}{l}-0.12 \\
(0.3)\end{array}$ & $\begin{array}{l}0.066 \\
(0.5)\end{array}$ & $\begin{array}{l}0.015 \\
(0.9)\end{array}$ & $(0.005)$ & $\begin{array}{l}0.15 \\
(0.2)\end{array}$ & $\begin{array}{l}-0.084 \\
(0.4)\end{array}$ & $\begin{array}{l}0.13 \\
(0.2)\end{array}$ & $\underset{\substack{0.042 \\
(0.7)}}{(0.7)}$ & \\
\hline MEgrey60 & $\begin{array}{l}-.03 \\
(0.005)\end{array}$ & $\begin{array}{l}0.004 \\
(0.4)\end{array}$ & 0.0038 & $\begin{array}{l}-0.18 \\
(0.09)\end{array}$ & $\begin{array}{l}.0 .027 \\
(0.8)\end{array}$ & $\begin{array}{l}0.013 \\
(0.9)\end{array}$ & $\begin{array}{l}.0 .12 \\
(0.3)\end{array}$ & $\begin{array}{l}-0.011 \\
(0.9)\end{array}$ & $\begin{array}{l}0.029 \\
(0.8)\end{array}$ & $\begin{array}{l}.0 .051 \\
(0.6)\end{array}$ & $\begin{array}{l}-0.049 \\
(0.7)\end{array}$ & \\
\hline MEgreenyellow & $\begin{array}{l}-0.14 \\
(0.2)\end{array}$ & $\begin{array}{l}0.11 \\
(0.3)\end{array}$ & $\begin{array}{l}0.24 \\
(0.02)\end{array}$ & $\begin{array}{l}-0.21 \\
(0.06)\end{array}$ & $\begin{array}{l}-0.18 \\
(0.09)\end{array}$ & $\begin{array}{l}.02 \\
(0.07)\end{array}$ & $\begin{array}{l}-0.18 \\
(0.09)\end{array}$ & $\begin{array}{l}-0.082 \\
(0.4)\end{array}$ & $\begin{array}{l}-0.048 \\
0.77)\end{array}$ & $\begin{array}{l}.0 .028 \\
(0.8)\end{array}$ & $\begin{array}{l}0.26 \\
(0.01)\end{array}$ & \\
\hline MEroyalblue & $\begin{array}{l}-0.11 \\
(0.3)\end{array}$ & $\begin{array}{l}0.12 \\
(0.3)\end{array}$ & $\begin{array}{l}0.12 \\
(0.3)\end{array}$ & $\begin{array}{l}-0.12 \\
(0.3)\end{array}$ & $\begin{array}{l}-0.15 \\
(0.2)\end{array}$ & $\begin{array}{l}-0.18 \\
(0.1)\end{array}$ & $\begin{array}{l}-0.16 \\
0.11\end{array}$ & $\begin{array}{l}0.1 \\
(0.4)\end{array}$ & $\begin{array}{l}.0 .012 \\
0.99)\end{array}$ & $\begin{array}{l}-60.04 \\
\text { (1) }\end{array}$ & $\begin{array}{l}-0.057 \\
(0.6)\end{array}$ & \\
\hline MEblue & $\begin{array}{l}-0.087 \\
(0.4)\end{array}$ & $\begin{array}{l}0.17 \\
(0.1)\end{array}$ & $\begin{array}{l}0.18 \\
(0.09)\end{array}$ & $\begin{array}{l}-0.24 \\
(0.03)\end{array}$ & $\begin{array}{l}.0 .095 \\
(0.4)\end{array}$ & $\begin{array}{l}-0.27 \\
(0.01)\end{array}$ & $\begin{array}{l}.0 .27 \\
(0.01)\end{array}$ & $\begin{array}{l}0.16 \\
(0.1)\end{array}$ & $\begin{array}{l}0.096 \\
(0.4)\end{array}$ & $\begin{array}{l}-0.038 \\
0.7)^{2}\end{array}$ & $\begin{array}{l}0.061 \\
(0.6)\end{array}$ & \\
\hline MEpurple & $\begin{array}{l}-0.3 \\
(0.004)\end{array}$ & $\begin{array}{l}0.13 \\
(0.2)\end{array}$ & $\begin{array}{l}0.32 \\
(0.022)\end{array}$ & $\begin{array}{c}-0.3 \\
(0.005)\end{array}$ & $\begin{array}{l}.0 .007 \\
(0.9)\end{array}$ & $\begin{array}{l}-0.21 \\
(0.05)\end{array}$ & $\underset{(40-04)}{-0.37}$ & $\begin{array}{l}0.059 \\
(0.6)\end{array}$ & $\begin{array}{l}0.13 \\
0.21\end{array}$ & $\begin{array}{l}0.031 \\
(0.8)\end{array}$ & $\begin{array}{l}-0.065 \\
(0.5)\end{array}$ & \\
\hline MEtan & $\begin{array}{l}-0.18 \\
(0.1)\end{array}$ & $\begin{array}{l}0.069 \\
(0.5)\end{array}$ & $\begin{array}{l}0.29 \\
(0.007)\end{array}$ & $\begin{array}{l}-0.22 \\
(0.04)\end{array}$ & $\begin{array}{l}0.0075 \\
(0.9)\end{array}$ & $\begin{array}{l}-0.14 \\
(0.2)\end{array}$ & $\begin{array}{l}.0 .33 \\
(0.002)\end{array}$ & $\begin{array}{l}0.21 \\
(0.06)\end{array}$ & $\begin{array}{l}0.11 \\
0.3)\end{array}$ & $\begin{array}{l}0.12 \\
(0.3)\end{array}$ & $\begin{array}{l}-0.16 \\
(0.1)\end{array}$ & -1 \\
\hline MEgrey & $\begin{array}{l}-0.17 \\
(0.1)\end{array}$ & $\begin{array}{l}-0.011 \\
0.99)\end{array}$ & $\begin{array}{l}0.029 \\
(0.8)\end{array}$ & $\begin{array}{l}-0.27 \\
(0.01)\end{array}$ & $\begin{array}{l}0.08 \\
(0.5)\end{array}$ & $\begin{array}{l}0.11 \\
(0.3)\end{array}$ & $\begin{array}{l}.0 .15 \\
(0.2)\end{array}$ & $\begin{array}{c}0.0073 \\
(0.9)\end{array}$ & $\begin{array}{l}-0.013 \\
0.99)\end{array}$ & $\stackrel{-0.0055}{(1)}$ & $\begin{array}{l}-0.15 \\
(0.2)\end{array}$ & \\
\hline & $\begin{array}{l}\text { TCGA. } \\
\text { subtybe }\end{array}$ & Gender & Age & os & Radio & Chemo & $\mathrm{IDH}$ & TP53 & EGFR & ATRX & EZH2 & \\
\hline
\end{tabular}

Figure 2. Module-trait associations were evaluated according to the correlations between MEs and clinical traits. Each row corresponds to an ME, while each column corresponds to a trait. Each cell contains the corresponding correlation (top line) and P-value (bottom line). The table is colour-coded by correlation, according to the coloured legend. ME, module eigengene; TCGA, The Cancer Genome Atlas; OS, overall survival; IDH, isocitrate dehydrogenase; TP53, tumour protein p53; EGFR, epidermal growth factor receptor; EZH2, enhancer of zeste homolog 2.

selected according to their degree of importance. The corresponding proteins may be the core proteins or key candidate genes that have significant physiological regulatory functions.

Survival analysis and validation of the genes in the TCGA dataset. To confirm the reliability of the identified genes from the CGGA data, GBM data from TCGA were then used to perform validation with the GEPIA database (http://gepia. cancer-pku.cn) (18). Through this database, the expression levels of all genes of interest in GBM and other tumours can be obtained. Furthermore, Kaplan-Meier curves were generated based on the GEPIA database. The OS was estimated using the log-rank test, and $\mathrm{P}<0.05$ was considered to denote statistically significant data.

KEGG analysis of IncRNA-correlated mRNAs in GBM. In TCGA data, mRNAs having a Spearman's correlation with lncRNA of $>0.4$ were considered to be lncRNA-correlated mRNAs. These were then analysed by KEGG pathway enrichment analysis. A P-value of $<0.05$ was applied to identify the significant pathways.

Further analysis of candidate lncRNAs in GBM. The genes nearby lncRNAs were analysed by genomic region enrichment of annotations tool (GREAT version 3.0.0) (19). The potential targets of IncRNA were predicted by searching the miRDB database (http://www.mirdb.org).

\section{Results}

Gene co-expression network of GBM. To detect and explore the possible biological function of the key survival-associated genes, WGCNA was performed based on the mRNA and lncRNA profiles derived from the CGGA database. According to the exclusion criteria mentioned earlier, RNA sequencing results and the clinical data of 88 GBM samples were downloaded from the CGGA database. For module detection, 5,000 coding and non-coding RNAs were selected for further analysis from the original 21,000 genes according to the standard deviation values. One outlier sample was removed from the sample network. The TCGA subtype, gender, age, OS, radiotherapy and chemotherapy information, and the mutation status of IDH, TP53, EGFR, ATRX and EZH2 were defined as clinical traits (Fig. 1A). Analysis of the network topology was first performed for various soft-thresholding power $\beta$ values to determine the relative balanced scale independence and mean connectivity of the weighted gene co-expression network. As shown in Fig. 1B, power 6 was the lowest power at which the scale-free topology 


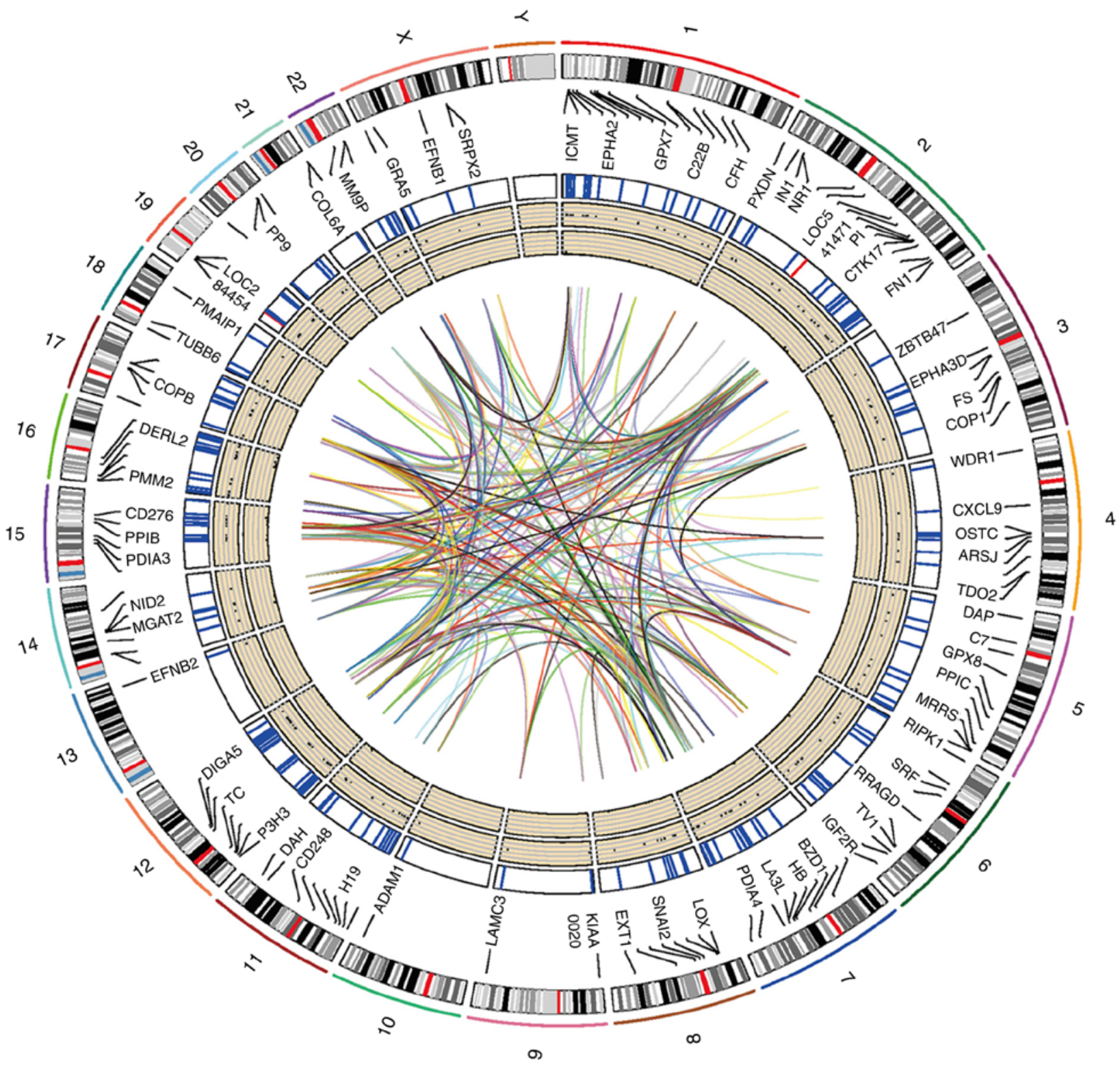

Figure 3. Identification of significant genes and their chromosomal locations in the purple module. The Circos plot shows the significant genes on the human chromosomes. From the outside and inwards, the first layer of the Circos plot is a chromosome map of the human genome; the black and white bars represent chromosome cytobands, while red bars represent centromeres. Due to limited space, a number of the genes are labelled in the second circle. In the third layer, coding and non-coding RNAs are marked in blue and red, respectively. The fourth layer represents the GS values of genes, while the innermost circle indicates the P-value of the GS. The network in the centre of the plot represents the core network. GS, gene significance.

fitting indices $r^{2}$ reached 0.90 ; thus, this power was selected in order to produce a hierarchical clustering tree (dendrogram) of the 5,000 genes. In total, 21 modules were identified by hierarchical clustering and dynamic branch cutting, and each module was assigned a unique colour as an identifier (Fig. 1C and D). The largest module contained 826 genes, while the smallest contained 58 genes. The grey module represented a gene set that was not assigned to any of the modules.

Identification of the modules significantly associated with survival. To explore the survival significance of the selected modules, correlations between the OS and module eigengenes were analysed. It was observed that three modules (black, brown and light cyan) were positively correlated with OS $(\mathrm{P}<0.05)$. Among them, the black module had the lowest P-value. Another five modules (turquoise, blue, purple, tan and grey) were negatively correlated with OS (Fig. 2; $\mathrm{P}<0.05$ ), with the purple module exhibiting the lowest P-value. According to the previous analysis of the survival significance of modules, the black and purple modules were selected for further analysis with OS, since they had the lowest P-values. Limited progress in targeted therapy for GBM has been made in recent years, and the majority of the therapeutic targets for this disease are oncogenes (20); thus, the purple module was further analysed in the present study, since the genes in purple module are considered to be oncogenes. In total, 195 genes, including 193 protein-coding and 2 non-coding genes, were identified in the purple module. The locations of certain of these identified genes on human chromosomes are displayed in the Circos plot in Fig. 3.

Enrichment analysis of coding genes in the purple module. The functions and pathway enrichment of the candidate 

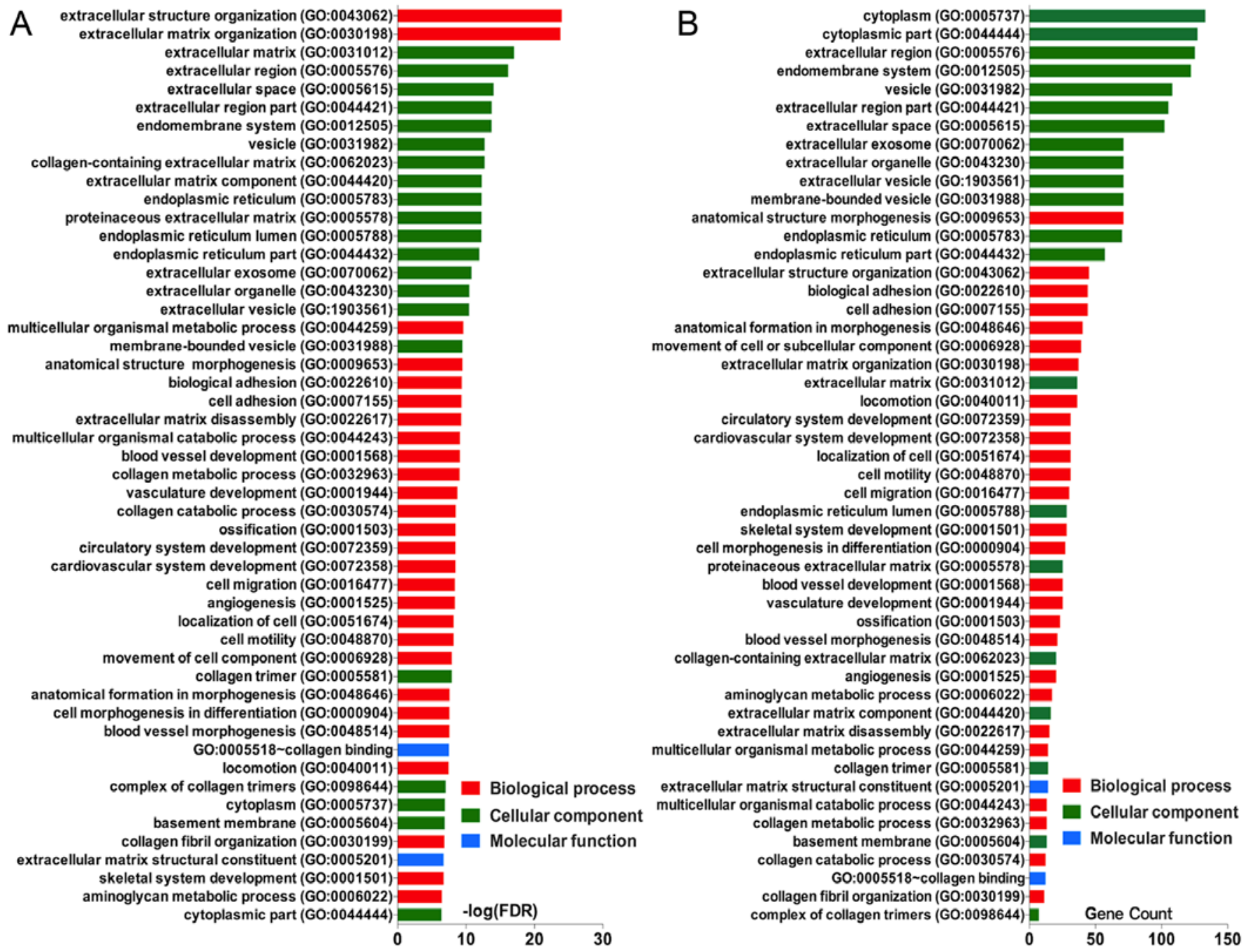

Figure 4. GO analysis and significantly enriched GO terms of significant genes in glioblastoma multiforme. GO analysis classified the significant genes into three categories: Biological process, molecular function and cellular component. (A) Top 50 significantly enriched GO terms ordered by (A) their function and (B) gene counts. GO, Gene Ontology.

genes in GBM identified from the purple module were analysed using multiple online databases, including the DAVID, Panther, KEGG pathway and STRING databases. The GO functional enrichments of genes were determined with the DAVID and Panther databases, with a P-value of $<0.05$ indicating statistical significance of the data. The protein-coding genes in the purple module were mapped to the GO database to determine their potential functions. GO terms were divided into three functional groups, including biological processes (BP), cell composition (CC) and molecular function (MF). The enriched GO terms for the genes are presented in Fig. 4. For the candidate genes in the purple module, the top three enriched GO terms in each category were as follows: Extracellular structure organisation, extracellular matrix (ECM) organisation and multicellular organismal macromolecule metabolic process in the BP category; ECM, extracellular region and extracellular space in the $\mathrm{CC}$ category; and collagen binding, ECM structural constituent and growth factor binding in the MF category (Fig. 4A and B). These results revealed that the majority of the genes were significantly enriched in extracellular structure, binding, cell parts and cell growth.
Subsequently, functional and signalling pathway enrichment of genes in the purple module was performed using the online databases DAVID, STRING and KEGG. The top enriched KEGG pathways for the candidate genes included ECM organisation, collagen formation, integrin cell surface interactions, degradation of the ECM, collagen biosynthesis and modifying enzymes, ECM proteoglycans, assembly of collagen fibrils and other multimeric structures, ECM-receptor interaction, collagen degradation and signalling by receptor tyrosine kinases (Fig. 5). The majority of the identified pathways were cancer-associated signalling pathways.

PPI network analysis of survival-associated coding genes in $G B M$. Data from the STRING database revealed that several of the genes interacted with each other. In total, 113 of the 193 candidate protein-coding genes were filtered to form the PPI network complex (Fig. 6). The network contained 113 nodes and 648 edges. Among the 113 nodes, the most significant 19 hub node genes were identified using a degree of $\geq 10$ as the filtering criterion. These genes were COL1A1, COL1A2, DCN, COL3A1, FN1, MMP9, COL6A1, COL5A2, COL6A2, ITGA5, FBN1, CTGF, ITGA4, PDGFRB, LUM, PPIB, 


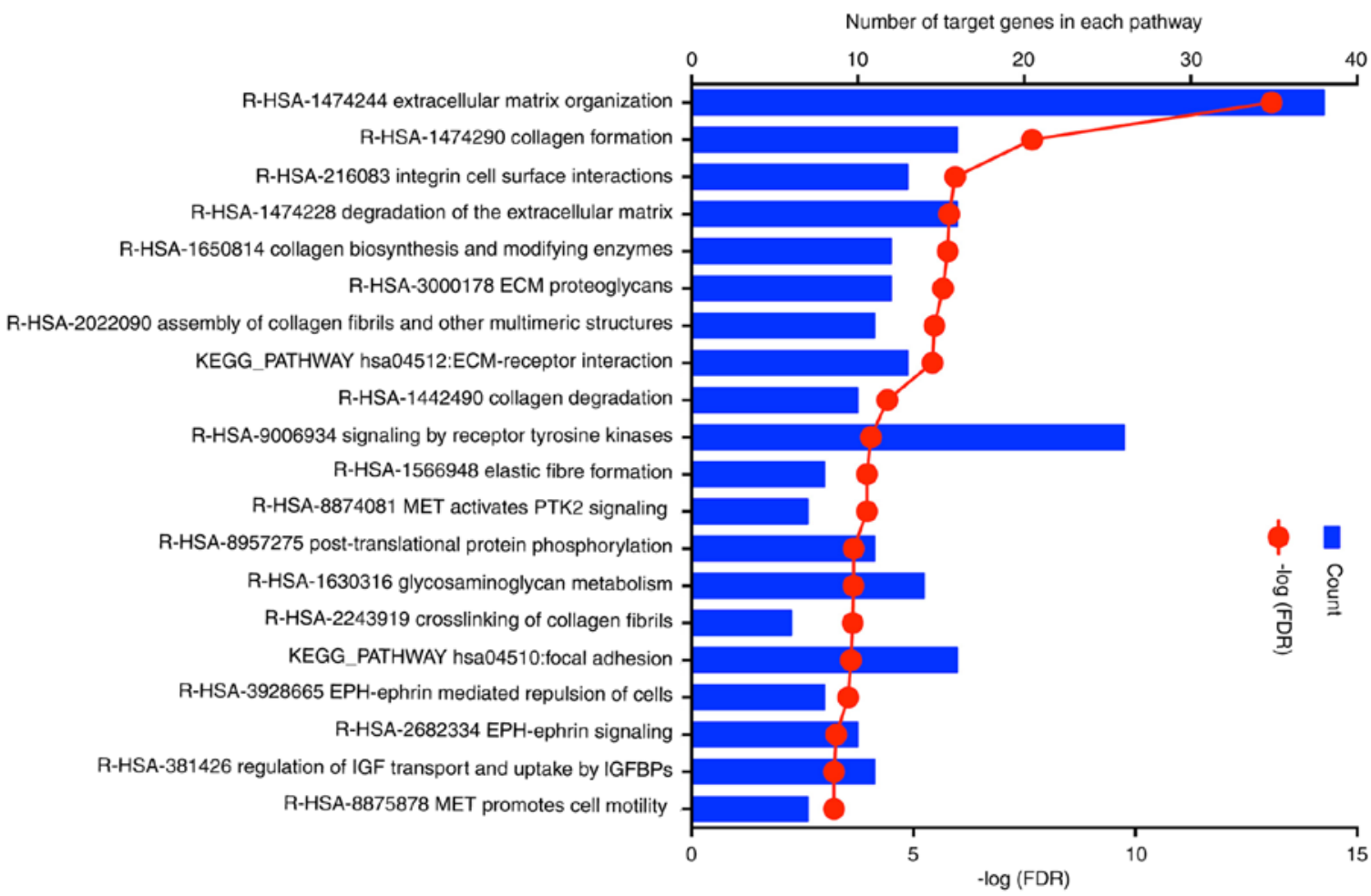

Figure 5. Significantly enriched pathways of significant genes in glioblastoma multiforme, included in the purple module. The top 20 enriched pathways are presented.

MMP14, ITGA11 and COPB1 (Table II). Among these genes, COL1A1 exhibited the highest node degree (degree $=30$ ), and FN1 shares the highest degree with 33 validated coding genes.

Validation of the survival-associated genes in TCGA dataset. To confirm the reliability of the 193 survival-associated coding genes identified from the CGGA, GBM datasets were also downloaded from TCGA database (including 162 GBM samples), and the RNA sequencing data and survival information of these datasets were subjected to Kaplan-Meier survival analysis. The results revealed significantly different OS between the high and low expression groups for 33 genes in the TCGA GBM, including ADAM12, B4GALT7, CD248, CHPF2, COL6A1, COL6A2, CYGB, DCBLD2, DERL2, DUSP6, EFNB2, EMILIN1, EPHA2, FAP, FBLN1, FN1, FZD1, HOXB2, HSP90B1, IGFBP4, LAMB1, LOXL1, MMP11, NID2, P4HB, PCOLCE, PDIA3, PLOD1, PMAIP1, PPIB, RARRES1, TBL2 and THY1 ( $<<0.05$; Fig. 7). Therefore, the expression levels of these 33 genes may be used as predictors of OS in GBM patients, indicating that they may be candidate genes involved in GBM that deserve further investigation.

Validation and survival analysis of candidate lncRNAs in $G B M$. According to the co-expression network, two lncRNAs, namely LOC541471 and LOC284494, were identified as survival-associated key non-coding genes in GBM. Next, the genes nearby these two lncRNAs were analysed. The results demonstrated that 8 genes were located near the transcription start site (Fig. 8A and B). To confirm the reliability of the identified lncRNAs, TCGA GBM data were subsequently used to perform validation by GEPIA. As shown in Fig. 8C, LOC541471 was significantly overexpressed in the GBM datasets obtained from TCGA. Next, the expression levels of these
Table II. Degrees of the top 19 key genes in the protein-protein interaction network.

\begin{tabular}{lc} 
Gene symbol & Degree \\
\hline COL1A1 & 30 \\
COL1A2 & 25 \\
DCN & 24 \\
COL3A1 & 22 \\
FN1 & 20 \\
MMP9 & 20 \\
COL6A1 & 18 \\
COL5A2 & 16 \\
COL6A2 & 16 \\
ITGA5 & 16 \\
FBN1 & 16 \\
CTGF & 14 \\
ITGA4 & 13 \\
PDGFRB & 12 \\
LUM & 11 \\
PPIB & 11 \\
MMP14 & 11 \\
ITGA11 & 11 \\
COPB1 & 10 \\
\hline
\end{tabular}

two lncRNAs in other types of cancer were explored using TCGA. It was observed that LOC541471 was overexpressed in 17 other cancer types (Fig. 8D), while LOC284494 was overexpressed in 3 other cancer types, as compared with their corresponding normal tissues (data not shown). Subsequently, 


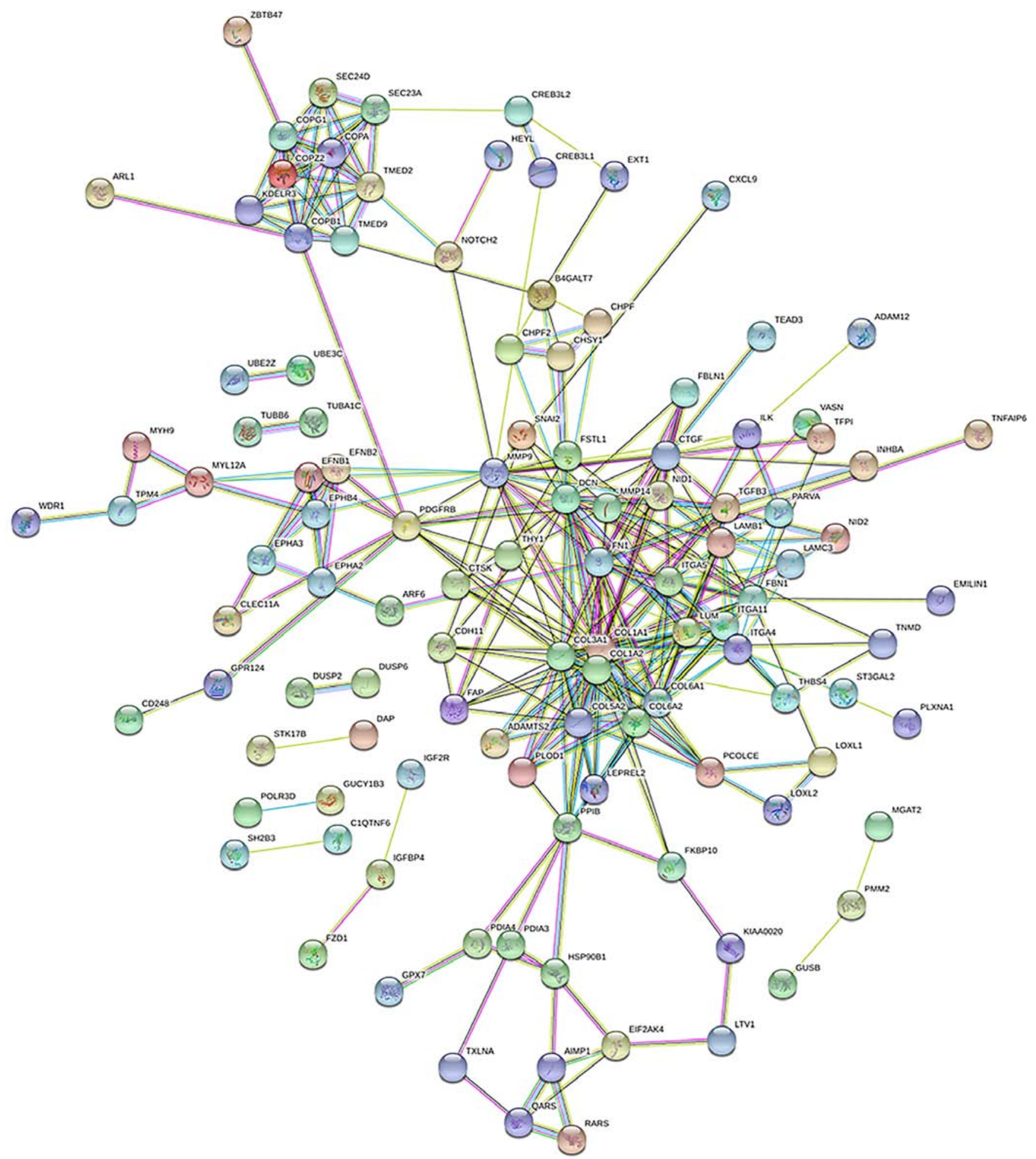

Figure 6. PPI network of the significant genes in glioblastoma multiforme. Using the STRING online database, 113 genes were selected and used to construct the PPI network. PPI, PPI, protein-protein interaction.

survival analysis was performed in the TCGA GBM data, and a significant association with survival was observed only for LOC541471 (Fig. 8E). Therefore, LOC541471 was regarded as a core IncRNA in the network and warrants further investigation.

Functional analysis of IncRNA LOC541471 in GBM. As mentioned earlier, LOC541471 was found to be the core
lncRNA in the co-expression network. To understand how this lncRNA is involved in GBM, a deeper insight into the GBM expression data from TCGA was required. Spearman's correlation of LOC541471 was calculated with $\sim 24,300$ coding genes in $156 \mathrm{GBM}$ patients. It was observed that pleckstrin-2 (PLEK2) is the mRNA exhibiting the highest correlation index $(r=0.68)$ with lncRNA LOC541471, and this gene is located on human chromosome 3p24.1 (Fig. 9A and B). According 

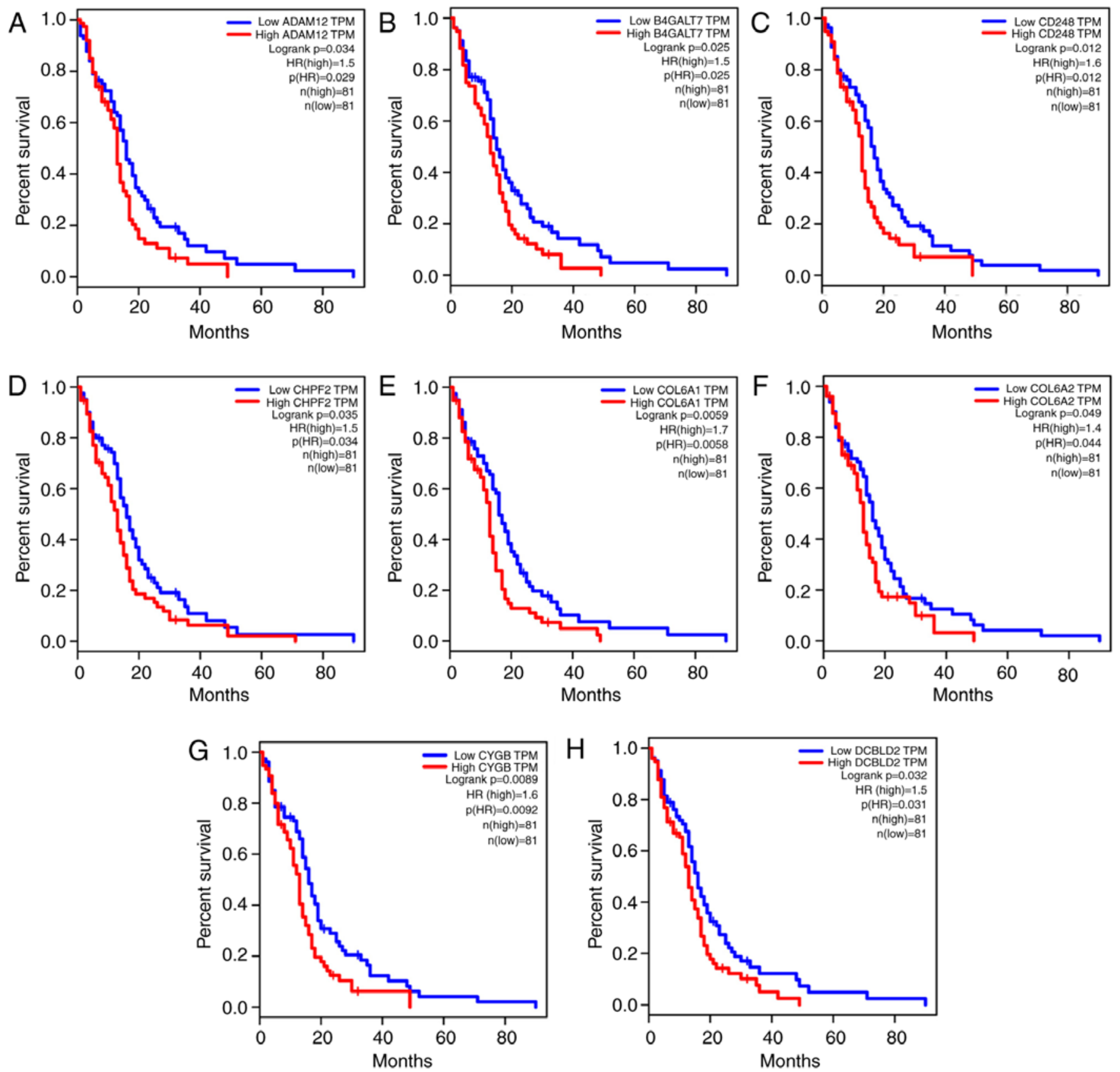

Figure 7. Survival rate calculated by the Kaplan-Meier survival curve in patients separated according to the median expression level of each gene, using data collected from The Cancer Genome Atlas. The top 8 of the 33 key genes are presented in the figure, while the analysis of the remaining genes is not shown. Survival curves of (A) ADAM12, (B) B4GALT7, (C) CD248, (D) CHPF2, (E) COL6A1, (F) COL6A2, (G) CYGB and (H) DCBLD2 are shown.

to the TCGA data, PLEK2 is significantly overexpressed in GBM tissues as compared with the normal tissue (Fig. 9C). Next, a total of 436 mRNAs that had a Spearman's correlation with LOC541471 of $>0.4$ were further examined by KEGG pathway analysis. Pathways were considered as enriched at a P-value of $<0.05$ (Fig. 9D), and the most enriched pathway was oxidative phosphorylation (OXPHOS). Finally, the expression data of GBM samples obtained from TCGA and CGGA were analysed, and the expression of LOC541471 in IDH1 wild-type was observed to be much higher compared with that in the IDH1 mutant group (Fig. 10).

Cytoplasmic lncRNAs can act as competing endogenous RNAs to modulate the functions of miRNAs (21). By searching the miRDB database (22), it was observed that LOC541471 was located in the cytoplasm, and 37 possible targets miRNAs were identified (Table III). The top 5 target miRNAs were hsa-miR-548t-3p, hsa-miR-548ap-3p, hsa-miR-548aa, hsa-miR-4288 and hsa-miR-3138. Taken together, these results predicted the potential mechanism of LOC541471; however, further studies are required to demonstrate this additional mechanism of LOC541471 in GBM.

\section{Discussion}

GBM is the most common and aggressive primary brain tumour type. The therapeutic options consist of microsurgery, and treatment with radiotherapy plus adjuvant chemotherapy with temozolomide and targeted drugs. Despite a large number 
A

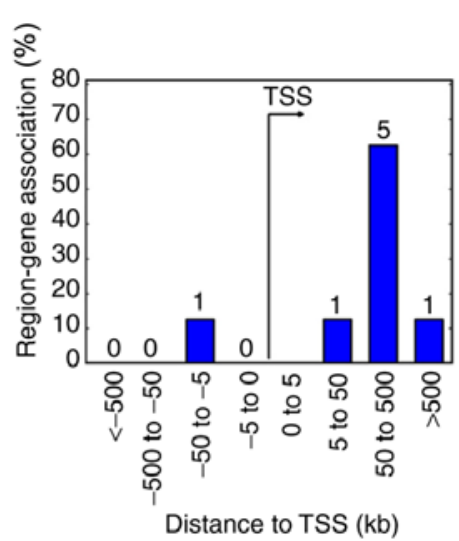

$\mathrm{B}$

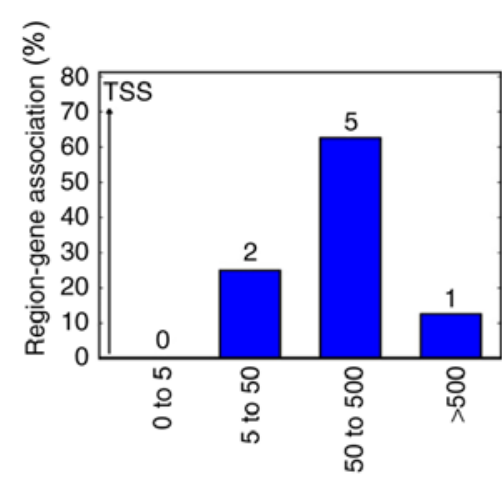

Absolute distance to TSS (kb)
C

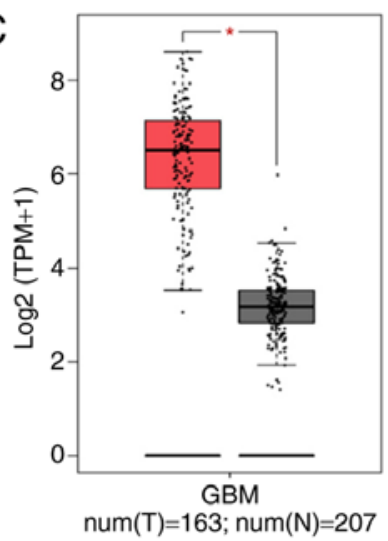

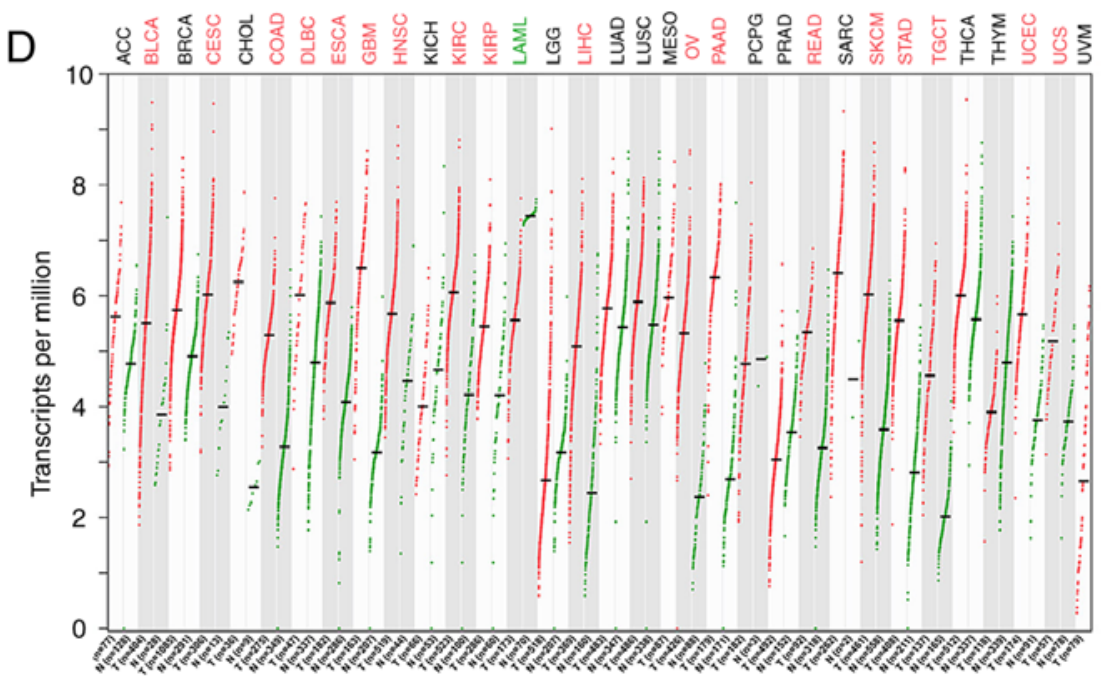

$E$

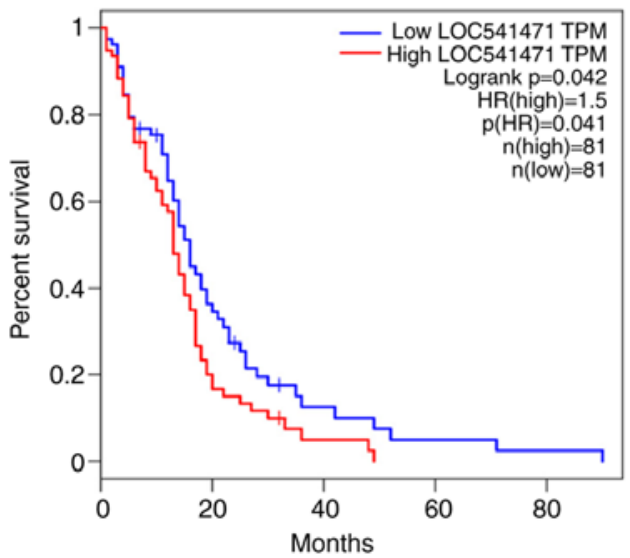

Figure 8. Location, expression and survival analysis of candidate lncRNAs in GBM data obtained from TCGA. (A) Distribution of the distances to the nearest transcription start site of the two lncRNAs. (B) Absolute distance to transcription start site. (C) Expression of LOC541471 in GBM and normal brain tissue. (D) Expression of LOC541471 in other tumours and corresponding normal tissues. (E) Kaplan-Meier analysis of the overall survival of patients with high or low LOC541471 expression levels in the TCGA dataset. lncRNA, long non-coding RNA; GBM, glioblastoma multiforme; TCGA, The Cancer Genome Atlas.

of basic and clinical studies that have revealed the mechanisms underlying the formation and development of GBM in the past decades, the prognosis for this disease remains considerably poor (23-25). Therefore, searching for new candidate genes is an important part of studying the disease tumourigenesis and would help identify novel therapeutic targets. A number of previous studies have used regulatory network methods to analyse gene expression data, and these approaches focus not only on the differences, but also on the correlations between gene expression datasets (26-28). Such studies have provided numerous relevant molecular mechanisms and valuable biomarkers for GBM. However, these methods use a hard threshold to determine the correlation between genes and do not consider the changes in the correlation intensity between genes under different conditions. Therefore, more appropriate methods are required.

WGCNA is a novel statistical method analysing gene correlations that is based on scale-free topology and construction of a weighted network via soft thresholds. It is not only used to construct gene networks and detect sub-networks, but also to identify hub genes and select candidate biomarker genes (8). In general, module checking in WGCNA requires a knowledge-independent process, and has been widely and successfully applied in biological function analysis in various diseases (29-31). Furthermore, it is well known that the mutation of genes contributes to GBM tumourigenesis; however, the role of lncRNAs has not yet been fully researched.

In the present study, a comprehensive analysis of IncRNA and mRNA profiling data of GBM patients obtained from the public database CGGA was performed. Subsequently, the modules associated with the OS of GBM cases were identified, the coding genes of the module were analysed by GO and KEGG enrichment analyses, and the PPI network was constructed. Next, genes associated with survival were identified by Kaplan-Meier survival analysis. Finally, the core lncRNAs and their biological functions were identified, and their expression was validated using the GBM dataset obtained from TCGA. In conclusion, our work has identified a gene set involving the survival and tumourigenesis of GBM in which lncRNAs play a critical role.

The gene expression profile of GBM obtained from CGGA was initially examined in the present study. A total of 5,000 genes with the lowest standard deviation values were selected, since these were considered as more likely to provide good data quality. Next, the purple module was identified by WGCNA, in which genes were significantly associated with OS of GBM patients. 
A $\operatorname{Chr} 14$

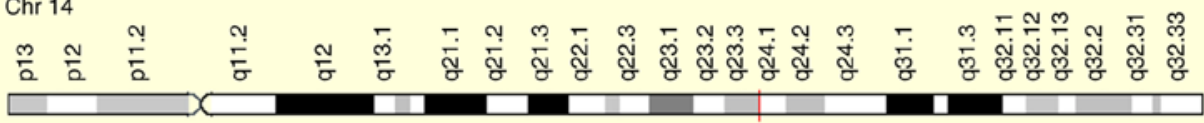
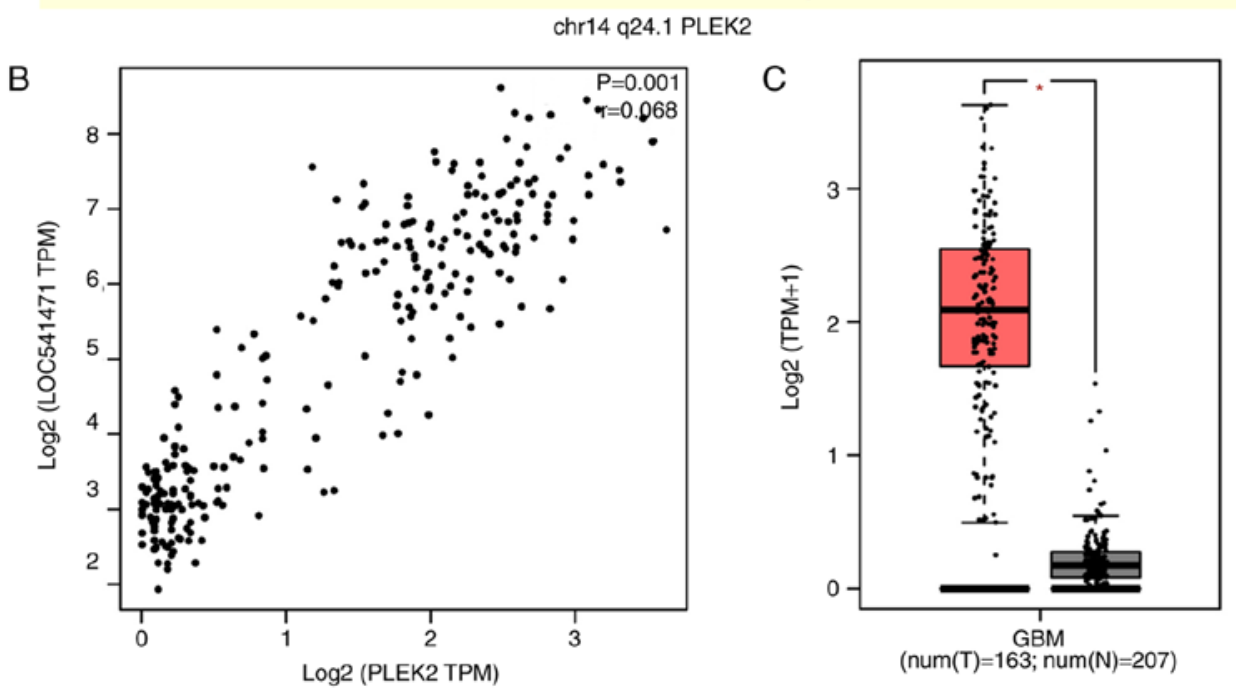

D

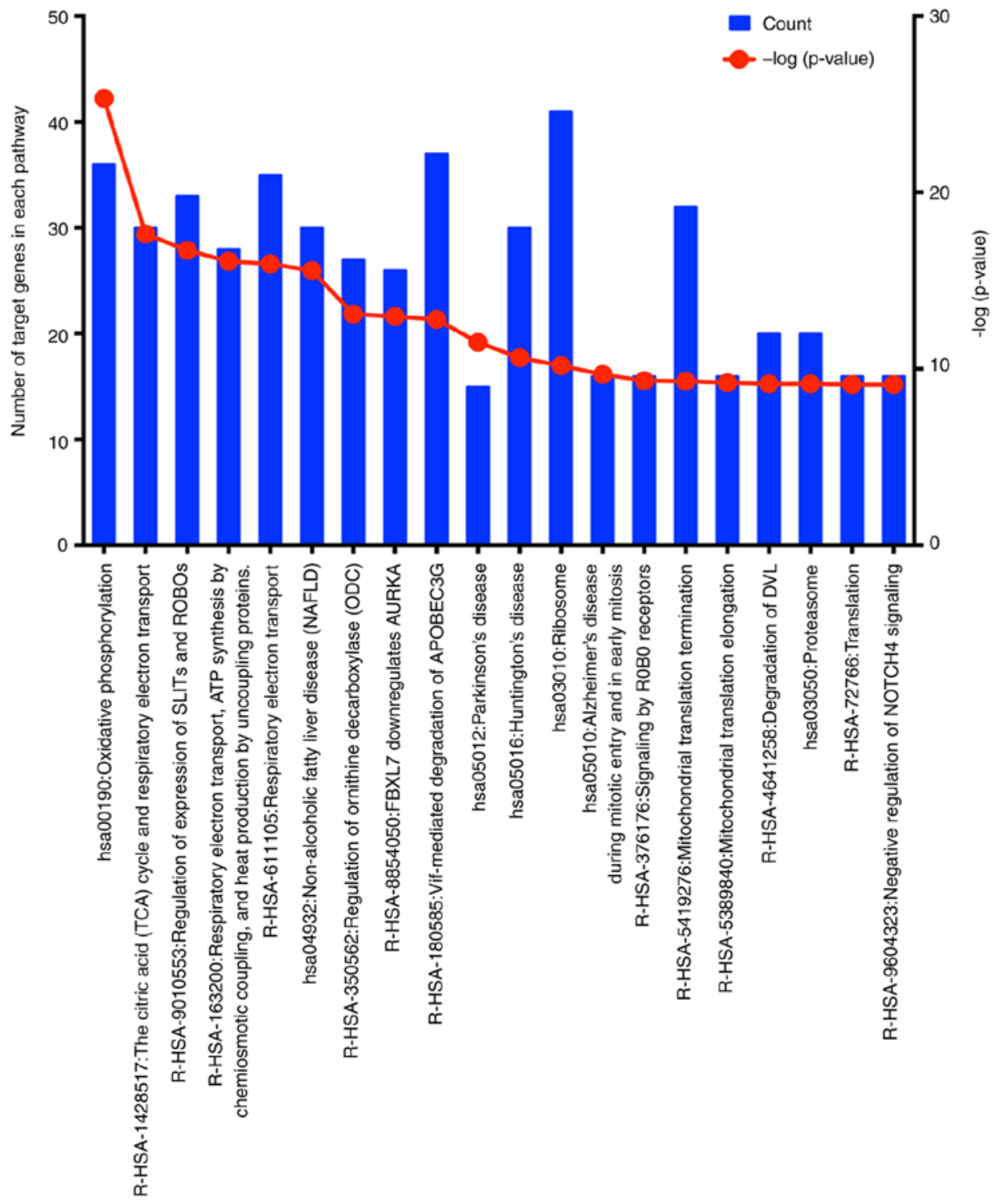

Figure 9. Functional analysis of 1ncRNA LOC541471 in GBM. (A) Schematic representation of the location of the PLEK2 gene on human chromosome 14q24.1. (B) Spearman's correlation analysis examining the association of LOC541471 with PLEK2 in the GBM dataset obtained from The Cancer Genome Atlas. (C) Expression of PLEK2 in GBM and normal brain tissue. (D) Top 20 significantly enriched pathways of all protein-coding genes with Pearson's correlation with LOC541471 of >0.4. IncRNA, long non-coding RNA; GBM, glioblastoma multiforme; PLEK2, pleckstrin-2. 
Table III. Predicted miRNAs targeted by LOC541471.

\begin{tabular}{|c|c|c|}
\hline Target rank & Target score & miRNA name \\
\hline 1 & 84 & hsa-miR-548t-3p \\
\hline 2 & 84 & hsa-miR-548ap-3p \\
\hline 3 & 84 & hsa-miR-548aa \\
\hline 4 & 82 & hsa-miR-4288 \\
\hline 5 & 77 & hsa-miR-3138 \\
\hline 6 & 76 & hsa-miR-93-3p \\
\hline 7 & 74 & hsa-miR-4508 \\
\hline 8 & 71 & hsa-miR-939-3p \\
\hline 9 & 69 & hsa-miR-5585-5p \\
\hline 10 & 68 & hsa-miR-4668-5p \\
\hline 11 & 66 & hsa-miR-4278 \\
\hline 12 & 66 & hsa-miR-4492 \\
\hline 13 & 65 & hsa-miR-2110 \\
\hline 14 & 65 & hsa-miR-519d-5p \\
\hline 15 & 64 & hsa-miR-3148 \\
\hline 16 & 63 & hsa-miR-1246 \\
\hline 17 & 62 & hsa-miR-4456 \\
\hline 18 & 62 & hsa-miR-1178-3p \\
\hline 19 & 61 & hsa-miR-3945 \\
\hline 20 & 61 & hsa-miR-4306 \\
\hline 21 & 60 & hsa-miR-877-3p \\
\hline 22 & 60 & hsa-miR-1302 \\
\hline 23 & 59 & hsa-miR-7975 \\
\hline 24 & 59 & hsa-miR-1252-5p \\
\hline 25 & 59 & hsa-miR-6853-3p \\
\hline 26 & 58 & hsa-miR-6794-5p \\
\hline 27 & 58 & hsa-miR-4716-3p \\
\hline 28 & 58 & hsa-miR-146b-3p \\
\hline 29 & 57 & hsa-miR-6754-5p \\
\hline 30 & 57 & hsa-miR-3622a-5p \\
\hline 31 & 57 & hsa-miR-542-3p \\
\hline 32 & 55 & hsa-miR-651-3p \\
\hline 33 & 55 & hsa-miR-1296-5p \\
\hline 34 & 55 & hsa-miR-1231 \\
\hline 35 & 54 & hsa-miR-136-5p \\
\hline 36 & 54 & hsa-miR-874-3p \\
\hline 37 & 54 & hsa-miR-4267 \\
\hline
\end{tabular}

Subsequent GO and KEGG pathway analyses of mRNAs in the purple module revealed that the majority of the genes were significantly enriched in extracellular structure, binding, cell part and cell growth. They were also involved in pathways relevant to tumour progression and migration, such as ECM organisation, collagen formation, integrin cell surface interactions, degradation of the ECM, collagen biosynthesis and modifying enzymes, and ECM-receptor interactions. These results can explain the correlations between the purple module and the OS of GBM patients.

According to the present study analysis, the top enriched GO terms were associated with ECM. It is well known that ECM is considered to be the key component in the spread of
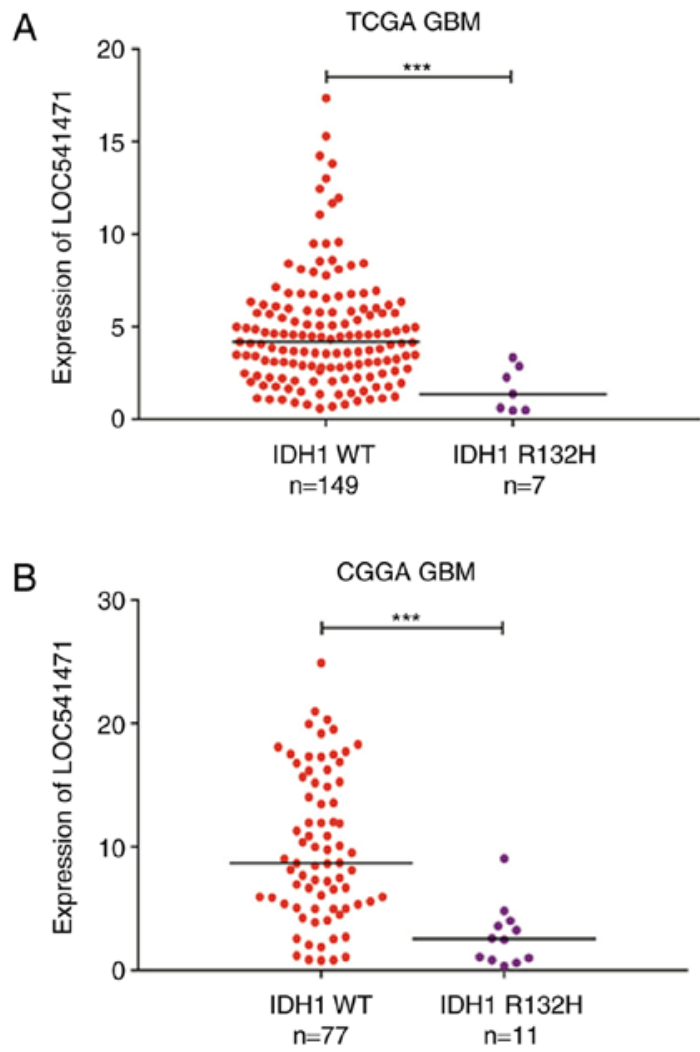

Figure 10. Association between LOC541471 and the IDH1 subtype of GBM. (A) Expression data of LOC541471 in the GBM dataset obtained from (A) TCGA and (B) CGGA. ${ }^{* * *} \mathrm{P}<0.001$. GBM, glioblastoma multiforme; CGGA, Chinese Glioma Genome Atlas; TCGA, The Cancer Genome Atlas; IDH1, isocitrate dehydrogenase 1.

gliomas throughout the brain (32). In addition, the ECM microenvironmental composition (33) and its mechanical force (34) influence the migration of glioma cells. ECM-binding proteins were considered to be indispensable elements of GBM migration (35). Furthermore, the degradation of ECM-components involves various proteases and hyaluronidases, which are important not only in promoting glioma cell migration by ECM decomposition, but also in releasing various growth and chemotactic factors that stimulate growth, survival and migration of GBM (36).

The current study identified 195 genes in the purple module, which were markedly associated with OS. Additionally, there were 33 candidate genes associated with the OS of patients with GBM according to TCGA data, and these may serve as prognostic biomarkers for GBM. Data from the STRING database further revealed that 113 genes of the 193 candidate protein-coding genes were filtered into the PPI network complex. Among these candidate genes, COL1A1 exhibited the highest degree in the network. COL1A1 encodes the major component of type I collagen, which is the fibrillar collagen found in the majority of connective tissues. Previous studies have reported that COL1A1 is upregulated in the microvasculature of proliferating GBMs (37). In addition, COL1A1 may be considered for use in stratifying patients with GBM into subgroups according to the risk of recurrence at diagnosis, as well as for prognostic and therapeutic evolution (38). These previous observations are consistent with the current research findings, suggesting that COL1A1 may also be a potential target for GBM therapy. 
The current study also identified that FN1 shares the highest degree with 33 validated coding genes. Fibronectin is a high-molecular-weight $(\sim 440 \mathrm{kDa})$ glycoprotein of the ECM that binds to membrane-spanning receptor proteins, known as integrins (39). Researchers have proven that FN1 is upregulated by TWIST1, which is known to promote epithelial-mesenchymal transition and/or GBM invasion (40). Furthermore, FN1 is associated with glioblastoma recurrence and can be regarded as a target for antiangiogenic therapy (41). The current study findings suggest that COL1A1 and FN1 are associated with migration, invasion, angiogenesis, recurrence and OS in GBM patients. Thus, these genes may serve important roles in the tumourigenesis of GBM.

The important roles of certain IncRNAs in GBM were clearly demonstrates in the current study. However, understanding the functions of these lncRNAs is challenging, since numerous lncRNAs are not included in the public databases. In the present study, it was demonstrated that LOC541471 was highly correlated with PLEK2 in GBM. Therefore, the biological functions of the lncRNA LOC541471 were further examined, and it was observed that it participates in the regulation of biological networks. KEGG pathway enrichment analysis for all protein-coding genes exhibiting Spearman's correlations with IncRNA LOC541471 of $>0.4$ revealed that the most enriched pathway was OXPHOS. OXPHOS is the metabolic pathway in which cells use enzymes to oxidise nutrients, thereby releasing energy that is used to produce adenosine triphosphate (42). This pathway serves an important role in the energy supply of GBM. Researchers have reported that IMP2 controls oxidative phosphorylation and is crucial for preserving glioblastoma cancer stem cells (43). Additionally, OXPHOS complexes may be clearly altered in GBM compared with normal brain tissue (44). Research progress in targeted therapies also indicates that the simultaneous targeting of glycolysis and OXPHOS is highly effective in blocking GBM tumourigenic phenotypes (45). Therefore, the present study results revealed that LOC541471 may serve a core role in the tumourigenesis of GBM, and may be a novel oncogene worth further study.

It should be noted that the current study examined a limited number of cases. The CGGA database only discloses a small part of the data, and these include gliomas from Grade I to Grade IV, as well as certain recurrent GBM cases. Therefore, only 88 cases met the requirements of the present study. It was attempted to add more data from other databases, however, standardisation of data from different sequencing platforms is not possible. Therefore, these 88 cases were selected for analysis. As more data become available in the CGGA database, more cases will be included in future studies.

In conclusion, using GBM data from the CGGA database and integrated WGCNA, a survival-associated gene module was identified, and 195 candidate key genes were obtained from this gene module. Among them, 33 key genes were proven to be correlated with OS, and the majority of the genes were involved in pathways associated with the ECM, ECM proteoglycans and tyrosine kinases receptor signalling. Furthermore, the IncRNA LOC541471 was identified as an OS-associated lncRNA, and appeared to serve a role in the OXPHOS of GBM through the PLEK2 gene. These findings may significantly enhance our understanding on the aetiology and underlying molecular events of GBM, and these candidate genes and pathways may serve as novel prognostic markers and potential therapeutic targets for GBM.

\section{Acknowledgements}

Not applicable.

\section{Funding}

This study was supported by the National Natural Science Foundation of China (grant nos. 81472661 and 81872048), the National Key Research and Development Program of China (grant no. 2016YFA0500303), the Beijing Municipal Natural Science Foundation (grant no. 7161004) and the Beijing Municipal Administration of Hospitals Clinical Medicine Development of Special Funding Support (grant no. ZYLX201608).

\section{Availability of data and materials}

The analysed datasets generated during the study are available from the corresponding author on reasonable request.

\section{Authors' contributions}

$\mathrm{XC}$, YSo and $\mathrm{LZ}$ conceived and designed the experiments. $\mathrm{CP}$, LK and XX performed the GO and PPI analyses. CX, YSu, YG collected and performed the WGCNA. ZZ, WZ and LH constructed the Circos plot and other figures. XC, YSo and LZ wrote the manuscript. All authors read and approved the final manuscript.

\section{Ethics approval and consent to participate}

Not applicable.

\section{Patient consent for publication}

Not applicable.

\section{Competing interests}

The authors declare that they have no competing interests.

\section{References}

1. Stoyanov GS and Dzhenkov DL: On the concepts and history of glioblastoma multiforme-morphology, genetics and epigenetics. Folia Med (Plovdiv) 60: 48-66, 2018.

2. Louis DN, Perry A, Reifenberger G, Von DA, Figarellabranger D, Cavenee WK, Ohgaki H, Wiestler OD, Kleihues P and Ellison DW: The 2016 World Health Organization classification of tumors of the central nervous system: A summary. Acta Neuropathol 131: 803-820, 2016.

3. Ostrom QT, Gittleman H, Liao P, Rouse C, Chen Y, Dowling J, Wolinsky Y, Kruchko C and Barnholtz-Sloan J: CBTRUS statistical report: Primary brain and central nervous system tumors diagnosed in the United States in 2007-2011. Neuro Oncol 16 (Suppl 4): iv1-iv63, 2014.

4. Stupp R, Mason WP, van den Bent MJ, Weller M, Fisher B, Taphoorn MJ, Belanger K, Brandes AA, Marosi C, Bogdahn U, et al: Radiotherapy plus concomitant and adjuvant temozolomide for glioblastoma. N Engl J Med 352: 987-996, 2005. 
5. Khasraw M, Ameratunga MS, Grant R, Wheeler $\mathrm{H}$ and Pavlakis N: Antiangiogenic therapy for high-grade glioma. Cochrane Database Syst Rev: CD008218, 2014.

6. Weller M, Butowski N, Tran DD, Recht LD, Lim M, Hirte H, Ashby L, Mechtler L, Goldlust SA, Iwamoto F, et al: Rindopepimut with temozolomide for patients with newly diagnosed, EGFRvIII-expressing glioblastoma (ACT IV): A randomised, double-blind, international phase 3 trial. Lancet Oncol 18 : 1373-1385, 2017.

7. Yan W, Zhang W, You G, Zhang J, Han L, Bao Z, Wang Y, Liu Y, Jiang C, Kang C, et al: Molecular classification of gliomas based on whole genome gene expression: A systematic report of 225 samples from the Chinese Glioma Cooperative Group. Neuro Oncol 14: 1432-1440, 2012

8. Langfelder P and Horvath S: WGCNA: An R package for weighted correlation network analysis. BMC Bioinformatics 9: 559, 2008.

9. Lv B, Zhang L, Miao R, Xiang X, Dong S, Lin T, Li K and Qu K: Comprehensive analysis and experimental verification of LINC01314 as a tumor suppressor in hepatoblastoma. Biomed Pharmacother 98: 783-792, 2018

10. Clarke C, Madden SF, Doolan P, Aherne ST, Joyce H, O'Driscoll L, Gallagher WM, Hennessy BT, Moriarty M,Crown J,et al: Correlating transcriptional networks to breast cancer survival: A large-scale coexpression analysis. Carcinogenesis 34: 2300-2308, 2013.

11. Liu XY, Gerges N, Korshunov A, Sabha N, Khuong-Quang DA, Fontebasso AM, Fleming A, Hadjadj D, Schwartzentruber J, Majewski J, et al: Frequent ATRX mutations and loss of expression in adult diffuse astrocytic tumors carrying IDH1/IDH2 and TP53 mutations. Acta Neuropathol 124: 615-625, 2012.

12. Brennan CW, Verhaak RG, McKenna A, Campos B, Noushmehr H, Salama SR, Zheng S, Chakravarty D, Sanborn JZ, Berman SH, et al: The somatic genomic landscape of glioblastoma. Cell 155: 462-477, 2013.

13. Ashburner M, Ball CA, Blake JA, Botstein D, Butler $\mathrm{H}$, Cherry JM, Davis AP, Dolinski K, Dwight SS, Eppig JT, et al: Gene ontology: Tool for the unification of biology. The Gene Ontology Consortium. Nat Genet 25: 25-29, 2000.

14. Kanehisa M: The KEGG database. Novartis Found Symp 247: 91-101; discussion 101-103, 119-128, 244-152, 2002.

15. Mi H, Dong Q, Muruganujan A, Gaudet P, Lewis S and Thomas PD: PANTHER version 7: Improved phylogenetic trees, orthologs and collaboration with the Gene Ontology Consortium. Nucleic Acids Res 38 (Database Issue): D204-D210, 2010.

16. Szklarczyk D, Franceschini A, Wyder S, Forslund K, Heller D, Huerta-Cepas J, Simonovic M, Roth A, Santos A, Tsafou KP, et al: STRING v10: Protein-protein interaction networks, integrated over the tree of life. Nucleic Acids Res 43 (Database Issue): D447-D452, 2015.

17. Shannon P, Markiel A, Ozier O, Baliga NS, Wang JT, Ramage D, Amin N, Schwikowski B and Ideker T: Cytoscape: A software environment for integrated models of biomolecular interaction networks. Genome Res 13: 2498-2504, 2003

18. Tang Z, Li C, Kang B, Gao G, Li C and Zhang Z: GEPIA: A web server for cancer and normal gene expression profiling and interactive analyses. Nucleic Acids Res 45: W98-W102, 2017.

19. McLean CY, Bristor D, Hiller M, Clarke SL, Schaar BT, Lowe CB, Wenger AM and Bejerano G: GREAT improves functional interpretation of cis-regulatory regions. Nat Biotechnol 28: 495-501, 2010.

20. Pagliarini R, Shao W and Sellers WR: Oncogene addiction: Pathways of therapeutic response, resistance, and road maps toward a cure. EMBO Rep 16: 280-296, 2015.

21. Yang F, Shen Y, Zhang W, Jin J, Huang D, Fang H, Ji W, Shi Y, Tang L, Chen W, et al: An androgen receptor negatively induced long non-coding RNA ARNILA binding to miR-204 promotes the invasion and metastasis of triple-negative breast cancer. Cell Death Differ 25: 2209-2220, 2018.

22. Wong $\mathrm{N}$ and Wang X: miRDB: An online resource for microRNA target prediction and functional annotations. Nucleic Acids Res 43 (Database Issue): D146-D152, 2015.

23. Mai WX, Gosa L, Daniels VW, Ta L, Tsang JE, Higgins B, Gilmore WB, Bayley NA, Harati MD, Lee JT, et al: Cytoplasmic p53 couples oncogene-driven glucose metabolism to apoptosis and is a therapeutic target in glioblastoma. Nat Med 23: $1342-1351,2017$.

24. Hu B, Wang Q, Wang YA, Hua S, Sauvé CG, Ong D, Lan ZD, Chang Q, Ho YW, Monasterio MM, et al: Epigenetic Activation of WNT5A drives glioblastoma stem cell differentiation and invasive growth. Cell 167: 1281-1295.e18, 2016

25. Furnari FB, Cloughesy TF, Cavenee WK and Mischel PS: Heterogeneity of epidermal growth factor receptor signalling networks in glioblastoma. Nat Rev Cancer 15: 302-310, 2015.
26. Guan X, Zhang C, Zhao J, Sun G, Song Q and Jia W: CMTM6 overexpression is associated with molecular and clinical characteristics of malignancy and predicts poor prognosis in gliomas. EBioMedicine 35: 233-243, 2018

27. Wanibuchi M, Ohtaki S, Ookawa S, Kataoka-Sasaki Y, Sasaki M, Oka S, Kimura Y, Akiyama Y, Mikami T, Mikuni N, et al: Actin, alpha, cardiac muscle 1 (ACTC1) knockdown inhibits the migration of glioblastoma cells in vitro. J Neurol Sci 392: 117-121, 2018.

28. Loriguet L, Morisse MC, Dremaux J, Collet L, Attencourt C, Coutte A, Boone M, Sevestre H, Galmiche A, Gubler B, et al: Combining genomic analyses with tumour-derived slice cultures for the characterization of an EGFR-activating kinase mutation in a case of glioblastoma. BMC Cancer 18: 964, 2108.

29. Busche S, Ge B, Vidal R, Spinella JF, Saillour V, Richer C, Healy J, Chen SH, Droit A, Sinnett D and Pastinen T: Integration of high-resolution methylome and transcriptome analyses to dissect epigenomic changes in childhood acute lymphoblastic leukemia. Cancer Res 73: 4323-4336, 2013.

30. Parikshak NN, Luo R, Zhang A, Won H, Lowe JK, Chandran V, Horvath S and Geschwind DH: Integrative functional genomic analyses implicate specific molecular pathways and circuits in autism. Cell 155: 1008-1021, 2013.

31. Cruchaga C, Karch CM, Jin SC, Benitez BA, Cai Y, Guerreiro R, Harari O, Norton J, Budde J, Bertelsen S, et al: Rare coding variants in the phospholipase D3 gene confer risk for Alzheimer's disease. Nature 505: 550-554, 2014.

32. Nakada M, Nakada S, Demuth T, Tran NL, Hoelzinger DB and Berens ME: Molecular targets of glioma invasion. Cell Mol Life Sci 64: 458-78, 2007.

33. Charles NA, Holland EC, Gilbertson R, Glass R and Kettenmann H: The brain tumor microenvironment. Glia 60: 502-514, 2012

34. Vargová L, Homola A, Zámecník J, Tichý M, Benes V and Syková E: Diffusion parameters of the extracellular space in human gliomas. Glia 42: 77-88, 2003.

35. Klank RL, Decker Grunke SA, Bangasser BL, Forster CL, Price MA, Odde TJ, SantaCruz KS, Rosenfeld SS, Canoll P, Turley EA, et al: Biphasic dependence of glioma survival and cell migration on CD44 expression level. Cell Rep 18: 23-31, 2017.

36. Kwiatkowska A and Symons M: Signaling determinants of glioma cell invasion. Adv Exp Med Biol 986: 121-141, 2013

37. Liu Y, Carson-Walter EB, Cooper A, Winans BN, Johnson MD and Walter KA: Vascular gene expression patterns are conserved in primary and metastatic brain tumors. J Neurooncol 99: 13-24, 2010.

38. Mikheeva SA, Mikheev AM, Petit A, Beyer R, Oxford RG, Khorasani L, Maxwell JP, Glackin CA, Wakimoto H, GonzálezHerrero I, et al: TWIST1 promotes invasion through mesenchymal change in human glioblastoma. Mol Cancer 9: 194, 2010.

39. Pankov R and Yamada KM: Fibronectin at a glance. J Cell Sci 115: 3861-3863, 2002

40. DeLay M, Jahangiri A, Carbonell WS, Hu YL, Tsao S, Tom MW, Paquette J, Tokuyasu TA and Aghi MK: Microarray analysis verifies two distinct phenotypes of glioblastomas resistant to antiangiogenic therapy. Clin Cancer Res 18: 2930-2942, 2012.

41. Janiszewska M, Suvà ML, Riggi N, Houtkooper RH, Auwerx J, Clément-Schatlo V, Radovanovic I, Rheinbay E, Provero P and Stamenkovic I: Imp2 controls oxidative phosphorylation and is crucial for preserving glioblastoma cancer stem cells. Genes Dev 26: 1926-1944, 2012.

42. Dimroth P, Kaim G and Matthey U: Crucial role of the membrane potential for ATP synthesis by F(1)F(o) ATP synthases. J Exp Biol 203: 51-59, 2000

43. Feichtinger RG, Weis S, Mayr JA, Zimmermann F, Geilberger R, Sperl W and Kofler B: Alterations of oxidative phosphorylation complexes in astrocytomas. Glia 62: 514-525, 2014.

44. Kennedy CR, Tilkens SB, Guan H, Garner JA, Or PM and Chan AM: Differential sensitivities of glioblastoma cell lines towards metabolic and signaling pathway inhibitions. Cancer Lett 336: 299-306, 2013.

45. Balbous A, Cortes U, Guilloteau K, Villalva C, Flamant S, Gaillard A, Milin S, Wager M, Sorel N, Guilhot J, et al: A mesenchymal glioma stem cell profile is related to clinical outcome. Oncogenesis 3: e91, 2014

This work is licensed under a Creative Commons Attribution-NonCommercial-NoDerivatives 4.0 International (CC BY-NC-ND 4.0) License. 